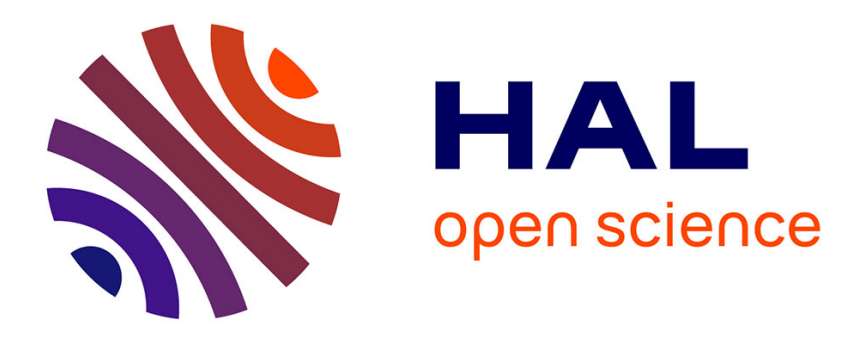

\title{
Pressure-to-depth conversion models for metamorphic rocks: derivation and applications
}

Arthur Bauville, Philippe Yamato

\section{To cite this version:}

Arthur Bauville, Philippe Yamato. Pressure-to-depth conversion models for metamorphic rocks: derivation and applications. Geochemistry, Geophysics, Geosystems, 2021, 22 (1), pp.e2020GC009280. 10.1029/2020GC009280 . insu-03097746v2

\section{HAL Id: insu-03097746 \\ https://hal-insu.archives-ouvertes.fr/insu-03097746v2}

Submitted on 20 Jan 2021

HAL is a multi-disciplinary open access archive for the deposit and dissemination of scientific research documents, whether they are published or not. The documents may come from teaching and research institutions in France or abroad, or from public or private research centers.
L'archive ouverte pluridisciplinaire HAL, est destinée au dépôt et à la diffusion de documents scientifiques de niveau recherche, publiés ou non, émanant des établissements d'enseignement et de recherche français ou étrangers, des laboratoires publics ou privés. 


\section{Geochemistry, Geophysics, Geosystems}

\author{
RESEARCH ARTICLE \\ 10.1029/2020GC009280 \\ Key Points: \\ - We present several pressure-to- \\ depth conversion models based on \\ mechanics and apply them to a data \\ set of metamorphic pressure \\ - The lithostatic pressure assumption \\ gives the upper estimate of depth at \\ peak pressure. The maximum depth \\ for our data set is $>150 \mathrm{~km}$ \\ - A change in stress state at a constant \\ depth $<75 \mathrm{~km}$ is enough to trigger \\ the commonly observed peak to \\ retrograde pressure decrease
}

Supporting Information:

- Supporting Information S1

- Data Set S1

Correspondence to:

A. Bauville,

abauville@jamstec.go.jp

\section{Citation:}

Bauville, A., \& Yamato, P. (2021). Pressure-to-depth conversion models for metamorphic rocks: Derivation and applications. Geochemistry, Geophysics, Geosystems, 22, e2020GC009280. https://doi.org/10.1029/2020GC009280

Received 30 JUN 2020

Accepted 4 DEC 2020
(C) 2020. American Geophysical Union. All Rights Reserved.

\section{Pressure-to-Depth Conversion Models for Metamorphic Rocks: Derivation and Applications}

\author{
Arthur Bauville $^{1}$ (D), and Philippe Yamato ${ }^{2,3}$ (D) \\ ${ }^{1}$ Japan Agency for Marine-Earth Science and Technology, Yokohama, Japan, ${ }^{2}$ Université de Rennes, CNRS, Géosciences \\ Rennes, Rennes, France, ${ }^{3}$ Institut Universitaire de France (IUF), Paris, France
}

\begin{abstract}
Pressure-to-depth conversion is a crucial step toward geodynamic reconstruction. The most commonly used pressure-to-depth conversion method assumes that pressure corresponds to the lithostatic pressure. However, deviatoric stresses can cause pressure to deviate from the lithostatic case strongly, thus adding considerable uncertainty to pressure to-depth conversion. First, we rederive formulas of pressureto-depth conversion that take into account deviatoric stresses. Then, we estimate the range of possible depth independently for each point in a data set containing peak and retrograde metamorphic pressure data (one-point method). In a second time, we use both the peak and retrograde pressure of a rock sample together, assuming that both pressures were recorded at the same depth (two-point method). We explore different cases to explain the transition from peak to retrograde pressure by varying the direction and magnitude of stresses. This alternative model is consistent with all data points but for a more restricted range of stress state and depth than the one-point model. Our results show that (1) even small deviatoric stresses have a significant impact on depth estimates, (2) the second principal stress component $\sigma_{2}$ plays an essential role, (3) several models can explain the pressure evolution of the data but lead to different depth estimates, and (4) strain data offer a mean to falsify our proposed two-point pressure-to-depth conversion. The maximum predicted depth at peak pressure is $170 \mathrm{~km}$ using the assumption that pressure is lithostatic, compared to $<75 \mathrm{~km}$ for our two-point model, which could correspond to the crustal root Moho's depth.
\end{abstract}

Plain Language Summary During the formation of mountain belts, rocks are buried deep in the Earth and then exhumed. In this journey, rocks undergo transformations that record the pressure. We use the pressure to estimate the depth at which a rock was buried to reconstruct the history of mountain belts. The pressure is the sum of the weight of the overlying column of rock and shear/volumetric stresses. However, since these stresses cannot be measured, there has been a long-standing debate on how much they influence the record of pressure in rocks. Here, we use mathematics and computer code to recalculate to recalculate the burial depth of a set of rock from pressure data. Two extreme scenarios emerge: (1) when ignoring tectonic forces (classical approach), we interpret the pressure history as the result of deep burial (up to $160 \mathrm{~km}$ ) followed by fast exhumation $(1-10 \mathrm{~cm} / \mathrm{yr}$ ) to $\sim 20 \mathrm{~km}$. The mechanism of such fast exhumation is itself intensely debated; (2) when considering tectonic forces, an alternative scenario is that the rock was buried to an intermediate depth $(<75 \mathrm{~km})$, followed by a change in tectonic forces without exhumation. If this second scenario is verified, then we must re-evaluate the history of mountain belts.

\section{Introduction}

Geodynamic reconstructions presenting cross-sections, maps, or elaborate large-scale plate reconstructions over time are essential to conceptualize lithospheric processes such as subduction or mountain building and to reconstruct Earth's history. These geodynamic reconstructions are based on quantitative data obtained with a wide range of techniques from field mapping to geophysical imaging. Among these data, pressure-temperature-time-deformation $(P-T-t-\epsilon)$ paths obtained from petrological, geochronological, and mineral deformation studies constitute key constraints. These features are indeed the only way to estimate the burial, temperature and deformation evolution of a piece of rock and, by extension, of the geological unit to which it belongs. In particular, estimated depths, in conjunction with geochronological data, are used to reconstruct the formation process of orogens (e.g., Agard et al., 2009; Chopin, 2003; Ernst et al., 2007). 
The conversion of pressure to depth is crucial in establishing a geodynamic reconstruction based on petrographic data. Depth can be retrieved from the lithostatic pressure $P_{\text {litho }}$, that is, the weight of the overlying column of rock, by the formula:

$$
z=\frac{P_{\text {litho }}}{\rho g},
$$

where $\rho$ is the average density of the rock column, $g$ is the gravitational acceleration and $z$ is depth, and under the assumption that $P_{\text {litho }}=0$ at $z=0$. However, $P_{\text {litho }}$ cannot be directly estimated from metamorphic rocks; instead, we can estimate the mean stress, also called the pressure, $P$ (Moulas et al., 2019). Note that $P=P_{\text {litho }}$ only in the case where deviatoric stresses are negligible. Therefore, an additional step is required to relate $P$ to $P_{\text {litho. This additional step involves information about the three-dimensional deviatoric stress }}$ state responsible for rock deformation. Unfortunately, deviatoric stresses cannot be measured, therefore,

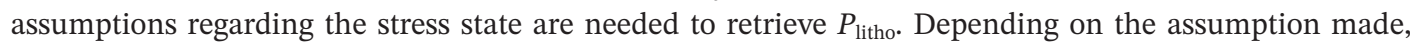
the final depth estimate can vary by more than a factor of two. Since these crucial assumptions are hard or maybe impossible to falsify, there has been a long-standing debate over (1) what is the most adequate stress state assumption to use for pressure-to-depth conversion, (2) how deeply were metamorphic rocks buried, and (3) how are metamorphic rocks exhumed (e.g., Agard et al., 2009; Brace et al., 1970; Ernst, 1963; Gerya, 2015; Godard, 2001; Green, 2005; Hobbs \& Ord, 2015; Hobbs \& Ord, 2017; Jamieson, 1963; Mancktelow, 1993; Moulas et al., 2013, 2019; Reuber et al., 2016; Schenker et al., 2015; Schmalholz \& Podladchikov, 2014; Tajčmanová, 2015; Wheeler, 2014; Yamato \& Brun, 2017).

The most common assumption is to ignore deviatoric stresses which follows from the argument that metamorphic rocks are assumed to be weak at the depths and temperature considered (e.g., Agard et al., 2009; Beltrando et al., 2007; Guillot et al., 2009; Rubatto et al., 2011). Thus, $P=P_{\text {litho }}$ and Equation 1 can be used. We call this assumption the "lithostatic case." In a rock, the magnitude of deviatoric stresses can vary from zero to the point of rock failure. Hence, the mean deviatoric stress can be of a magnitude comparable to lithostatic pressure, and $P$ can vary from 1 to 2 times the value of $P_{\text {litho }}$ in compression for a homogeneous rock (Petrini \& Podladchikov, 2000). The difference between $P$ and $P_{\text {litho }}$ is referred to as "tectonic pressure" (N. S. Mancktelow, 2008), "tectonic overpressure" (Mancktelow, 1993; Schmalholz \& Podladchikov, 2013) or simply "overpressure" when it is positive or "underpressure" when it is negative (Moulas et al., 2013). Therefore, it is essential to consider variations in the stress state when interpreting pressure-temperature $(P-T)$ paths. Note that the overpressure model is a general model of which the "lithostatic case" constitutes one special case. In addition, (1) the presence of topography and crustal roots in mountain belts always cause deviation of pressure from the lithostatic case (Schmalholz et al., 2014, 2019); (2) even rocks with no deviatoric stress can experience of pressure that deviates significantly from the lithostatic case depending on the local geometry (Moulas et al., 2014; Schmalholz \& Podladchikov, 2013); (3) density changes, which we do not consider in this article, can also locally modify the pressure (Vrijmoed et al., 2010).

In most cases, the $P-T$ evolution of a (ultra-)high pressure ([U]HP) metamorphic rock can be approximated by three linear segments. A prograde segment (highlighted in blue in Figure 1a) that shows increases in both $P$ and $T$ and a retrograde part (in green in Figure 1a) divided in two segments: a retrograde stage 1 and a retrograde stage 2 (see Figure 1a). The first stage of the retrograde path generally shows a large decrease in pressure and only minor variations in temperature, while the second stage presents decreases in both pressure and temperature conditions (see Yamato \& Brun, 2017). Hereafter, we use the notations $P_{p}$ and $T_{p}$ to refer to the pressure and temperature conditions at the peak of (U)HP metamorphism (time $t_{1}$ in Figure 1a), respectively. Similarly, $P_{r}$ and $T_{r}$ refer to the pressure and temperature conditions at the end of retrograde stage 1 (time $t_{2}$ in Figure 1a).

There are arguably two events in the $P-T$ path that cause most of the debate: peak metamorphism $\left(P_{p}\right.$, $\left.T_{p}\right)$ and retrograde stage 1 (i.e., the transition from $P_{p}$ to $P_{r}$ ). Thermobarometric studies often provide $P_{p}, T_{p}$ and $P_{r}, T_{r}$, sometimes in association with geochronological dating. We present the data set of $P_{p}, T_{r}-P_{r}, T_{r}$ collected from the literature in the $P-T$ space in Figure 1b and in the space $P_{p}-P_{r}$ in Figure 1c. In $P_{p}-P_{r}$ space, most data points are contained within a fan centered on 0 , which suggests that $P_{p}$ and $P_{r}$ are proportional, with coefficients of proportionality, $P_{p} / P_{r}$, between 2.4 and 4.8. A few data points with values $P_{p}<1.5$ have a coefficient of proportionality $<2.4$ as low as 1.4 . We term these points "Others (outliers)." 
(a)

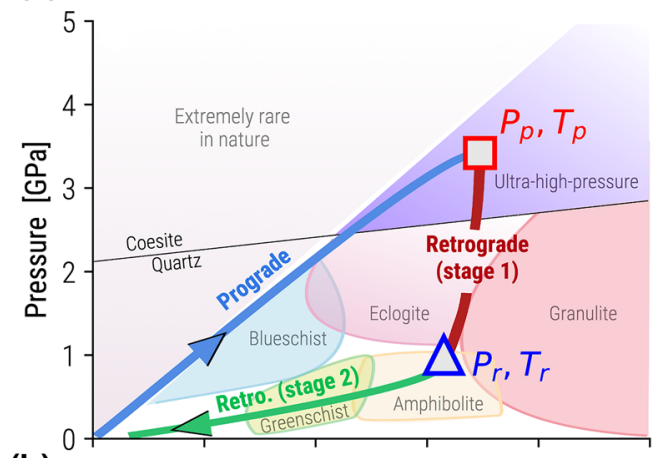

(b)

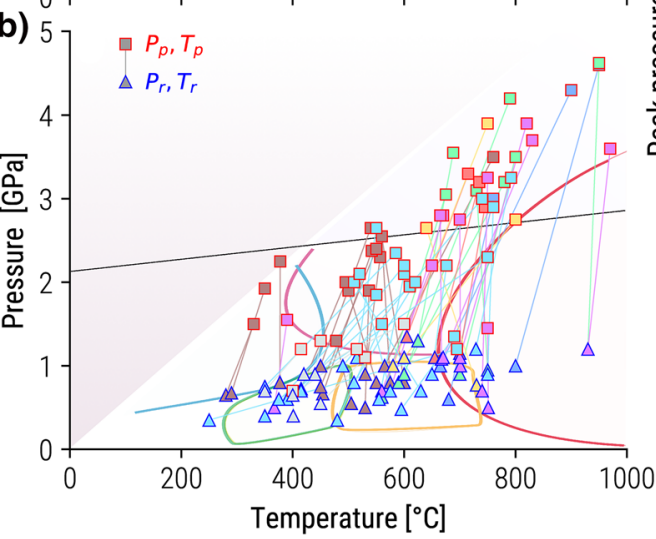

(c)

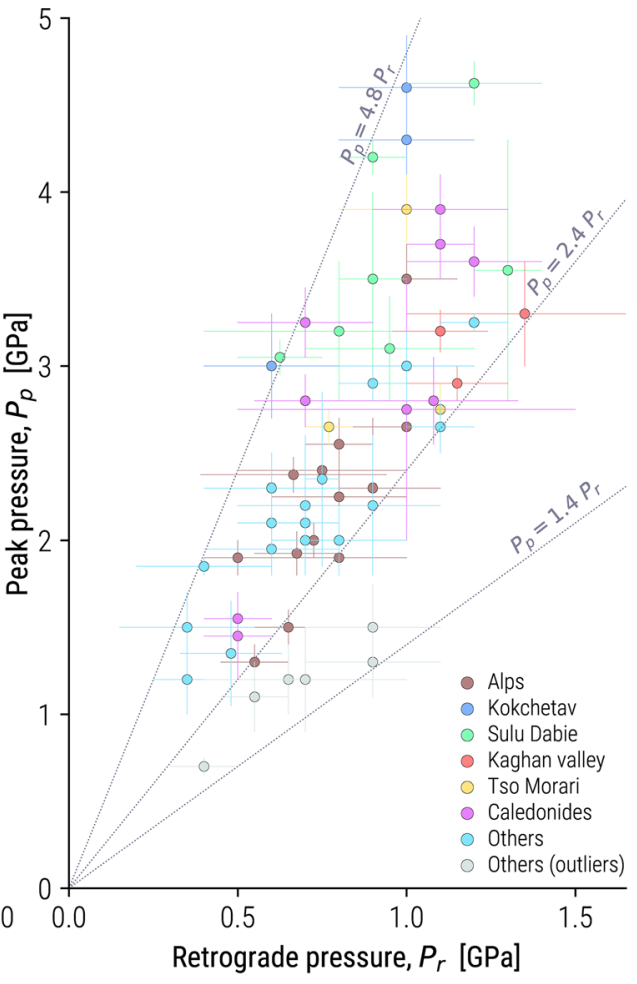

Figure 1. (a) Typical example of a $P-T$ path. (b) Data set in $P-T$ space. Colors correspond to the orogenic system from which data come as presented in C. (c) Repartition of the data (see supporting information for references) in a $P_{p}$ versus $P_{r}$ diagram.

To illustrate the consequence of stress state assumptions on geodynamic interpretations, let us consider a rock presenting a mineral paragenesis equilibrated at 3.0 GPa. This rock can be interpreted as having been buried up to $100 \mathrm{~km}$ depth under the "lithostatic" assumption (using $\rho g=28,000 \mathrm{~kg} / \mathrm{m}^{2} / \mathrm{s}^{2}$ ) but only $\sim 50 \mathrm{~km}$ when considering a magnitude of deviatoric stresses close to the brittle yield stress in compression. While the former corresponds to mid-lithospheric depth, the latter would correspond to crustal-root depth. Pleuger and Podladchikov (2014), for example, proposed a geodynamic reconstruction of the central Alps based on structural arguments wherein the Adula nappe, an eclogite-bearing metamorphic unit in the Alps, was buried to $50-60 \mathrm{~km}$ depth. This depth estimate implies an overpressure of $40 \%-80 \%$ of the lithostatic pressure and suggests that the burial and exhumation of this unit occurred within an orogenic crustal wedge. In alternative models using the "lithostatic assumption," the nappe was buried to $80 \mathrm{~km}$ depth during subduction and then rapidly exhumed by slab breakoff (Froitzheim et al., 2003; Schmid et al., 1996) or subvertical extreme thinning (Nagel, 2008). The scenario of Schmid et al. (1996) employs one subduction zone in conjunction with a normal fault, while the models of Froitzheim et al. (2003) and Nagel (2008) involve two subduction zones. Thus, different assumptions regarding pressure-to-depth conversion lead to different interpretations of the process of mountain building. Therefore, it is crucial to understand, compare, and evaluate the implications of different assumptions about the stress state when designing geodynamic reconstructions.

Retrograde stage 1, when the pressure decreases from $P_{p}$ to $P_{r}$ in a relatively short amount of time, is also at the center of heated debate. Using the "lithostatic assumption," the transition from $P_{p}$ to $P_{r}$ is interpreted as an exhumation event. In conjunction with dating data, this phase of exhumation is generally interpreted as fast, with exhumation rates comparable to subduction rates (1-10 cm/yr) (e.g., Rubatto \& Hermann, 2001; Parrish et al., 2006). Various mechanisms have been proposed to explain these fast exhumation rates, such as buoyancy-driven exhumation (Beaumont et al., 2009; E. Burov et al., 2014; Butler et al., 2013, 2014; Schmalholz \& Schenker, 2016; Wheeler, 1991), slab breakoff (Huw Davies \& von Blanckenburg, 1995), 
Table 1

List of Notation

\begin{tabular}{|c|c|c|}
\hline Symbol & Meaning & Unit \\
\hline$x, y, z$ & Components of the spatial carthesian coordinate system ( $z$ is vertical) & $m$ \\
\hline$\sigma_{x}, \sigma_{y}, \sigma_{z}$ & Normal components of the total stress tensor & $P a$ \\
\hline$\sigma_{1}, \sigma_{2}, \sigma_{3}$ & Principal stresses & $P a$ \\
\hline$\Delta \sigma_{x}$ & Horizontal tectonic stress & $P a$ \\
\hline$\sigma_{n}, \tau$ & Normal and shear stress (used in Mohr diagrams) & $P a$ \\
\hline$P$ & Pressure or mean stress & $\mathrm{Pa}$ \\
\hline $\bar{\sigma}, \bar{\tau}, \bar{P}$ & Normal stress, shear stress and pressure when normalized by $\sigma_{z}$ & - \\
\hline$\alpha$ & Factor that determines the value of $\sigma_{2}$ as a function of $\sigma_{3}, \sigma_{1}$ & - \\
\hline$\rho$ & Average density of rocks & $\mathrm{kg} \cdot \mathrm{m}^{-3}$ \\
\hline$g$ & Gravity acceleration & $m \cdot s^{-2}$ \\
\hline$\Phi$ & Friction angle & - \\
\hline$\theta$ & Angle between $\sigma_{1}$ and the horizontal & - \\
\hline$F$ & Yield function & - \\
\hline
\end{tabular}

normal faulting (Platt, 1986; Ring et al., 1999; Schmid et al., 1996), rollback (Brun \& Faccenna, 2008), or channel flow (e.g., Guillot et al., 2009). These and other mechanisms are discussed in detail in several reviews (Guillot et al., 2009; B. R. Hacker \& Gerya, 2013; Warren, 2013). In contrast to the fast exhumation interpretation, Yamato and Brun (2017) showed that when considering the large deviatoric stresses assumption, the transition from $P_{p}$ to $P_{r}$ can be explained, for many rock samples, by a switch from a compressional to an extensional stress state without exhumation.

In this contribution, we first review the mathematical background of pressure and stress. Then, we formulate a "one-point method" of pressure-to-depth conversion to estimate depth based on a single pressure data point and a "two-point method" that uses both $P_{p}$ and $P_{r}$ with the assumption that $z_{p}=z_{r}$. We apply these methods to our data set (Figure 1b) to determine an estimated depth range for each sample. Finally, we discuss the consequences of different assumptions for geodynamic interpretation and point out ways of falsifying some assumptions. Our goal is both to raise awareness about the issue of pressure-to-depth conversion and to provide tools allowing one to perform such conversion easily. For this reason, we provide computer codes (Jupyter notebooks) as supporting information S2-S10. These scripts allow readers to reproduce most of the figures presented in this article readily and to extend the database with their own data. The codes can also be used to experiment with stress states and material properties.

\section{One-Point Method of Pressure-to-Depth Conversion}

\subsection{Overview of the Model}

\subsubsection{Sketch, Coordinate System and Equations of Stress}

Let us consider an ideal and simplified orogen submitted to horizontal tectonic stresses in a three-dimensional Cartesian orthonormal system $(x, y, z)$ where $z$ is vertical and points downward, and $x$ is the direction in which tectonic loading is applied (Figure 2a). $\sigma_{x}, \sigma_{y}, \sigma_{z}$ are the normal components of the stress tensor in this coordinate system, and $\sigma_{1}, \sigma_{2}, \sigma_{3}$ are the principal stresses. We use the convention that stresses are positive in compression. All notations are listed in Table 1. We assume that the topography is flat, so we ignore sources of overpressure due to variations of gravity potential energy (Schmalholz et al., 2014). We also assume the material is homogeneous. We assume, in a first step, that the stress state is Andersonian, that is, one principal stress direction is vertical, and the other two are horizontal (Anderson, 1905). We fix the $y$-axis in the direction of $\sigma_{2}$. Thus, we only consider cases where the stress state can induce normal or reverse faulting, and we ignore the stress states that would result in strike-slip faulting. We will treat the case of 
Lithostatic

Extension

Compression

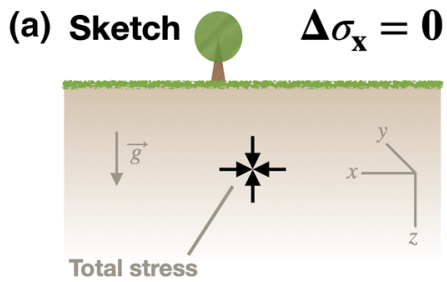

$\Delta \sigma_{\mathrm{x}}<\mathbf{0}$

$\Delta \sigma_{\mathbf{x}}>\mathbf{0}$

Total stress

Deviatoric or

"tectonic" stress, $\Delta \sigma_{x}$

(b) Equations

$\sigma_{1}=\sigma_{2}=\sigma_{3}=\rho g z$

$\left\{\begin{array}{l}\sigma_{1}: \sigma_{z}=\rho g z \\ \sigma_{2}: \sigma_{y}=\alpha \sigma_{z}+(1-\alpha) \sigma_{x} \\ \sigma_{3}: \sigma_{x}=\sigma_{z}+\Delta \sigma_{x}\end{array}\right.$

$\left\{\begin{array}{l}\sigma_{1}: \sigma_{x}=\sigma_{z}+\Delta \sigma_{x} \\ \sigma_{2}: \sigma_{y}=\alpha \sigma_{x}+(1-\alpha) \sigma_{z} \\ \sigma_{3}: \sigma_{z}=\rho g z\end{array}\right.$

$\sigma_{x}=\sigma_{y}=\sigma_{z}=\rho g z$

(c) Deformation regime

$$
\begin{array}{cccccc}
\alpha=0 & \alpha=1 / 2 & \alpha=1 & \alpha=0 & \alpha=1 / 2 & \alpha=1 \\
\left(\sigma_{2}=\sigma_{3}\right) & \left(\sigma_{2}=P\right) & \left(\sigma_{2}=\sigma_{1}\right) & \left(\sigma_{2}=\sigma_{3}\right) & \left(\sigma_{2}=P\right) & \left(\sigma_{2}=\sigma_{1}\right)
\end{array}
$$

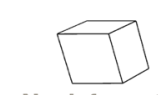

No deformation

\section{Deformed}
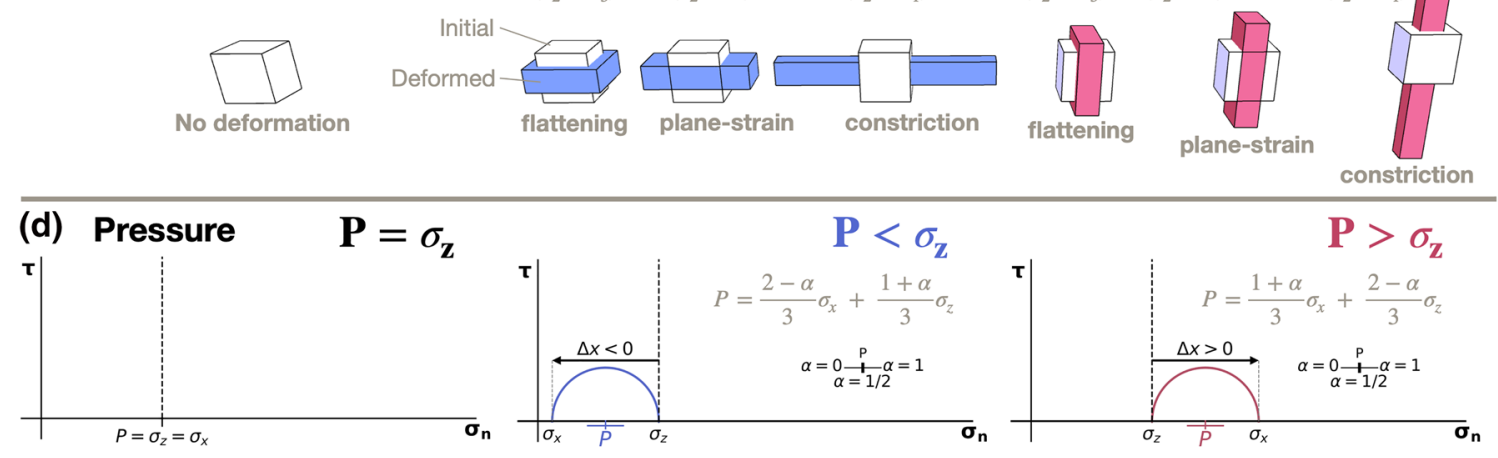

(e) Maximum $\Delta \sigma_{x} \quad \sigma_{\mathrm{x}}=\sigma_{\mathrm{z}}$

$$
\sigma_{\mathrm{z}} / \Phi<\sigma_{\mathrm{x}}<\sigma_{\mathrm{z}}
$$

$$
\sigma_{\mathrm{z}}<\sigma_{\mathbf{x}}<\Phi \sigma_{\mathrm{z}}
$$
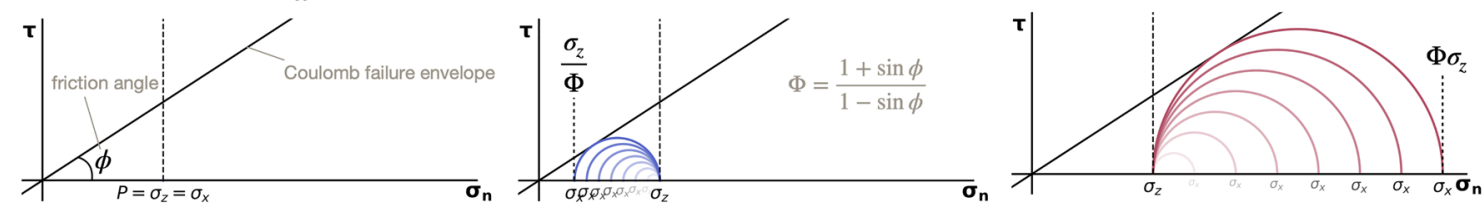

(f) Summary Non-dimensionalization: $\bar{X}=\frac{X}{\sigma_{z}}$ - stress quantity

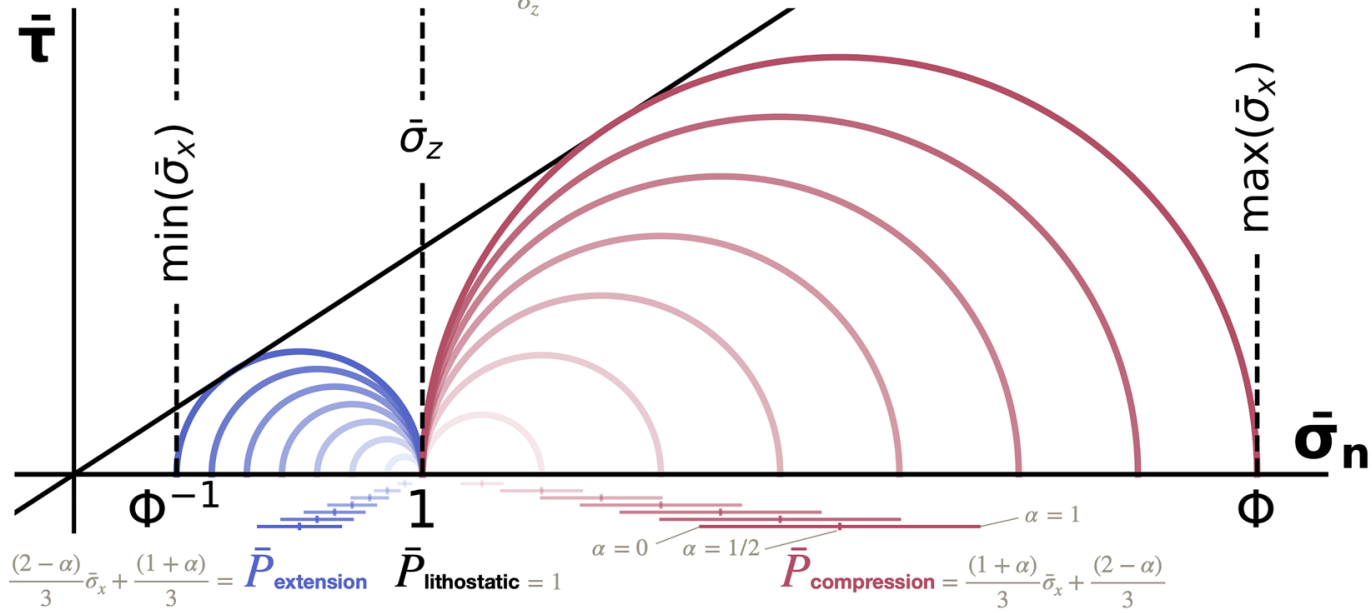

Figure 2. Overview of the principal characteristics of the model and definitions. See text for details concerning notation. $\Delta \sigma_{x}$ corresponds to the stress magnitude applied in the $x$-direction. Graphics presenting $\sigma_{n}$ versus $\tau$ (i.e., normal stress vs. shear stress) correspond to Mohr diagrams. 
non-Andersonian stresses in Section 3.2. Under these assumptions, the total vertical stress $\sigma_{z}$ corresponds to the weight of the column of rock above the considered point (or $P_{\text {litho }}$ ) and is given by:

$$
\sigma_{z}=\rho g z
$$

where $\rho$ is the density of the overlying rocks, $g$ is the gravitational acceleration and $z$ is the depth where the computation is performed. When a tectonic stress of magnitude $\Delta \sigma_{x}$ is applied in the $x$-direction, the following equation applies:

$$
\sigma_{x}=\sigma_{z}+\Delta \sigma_{x}
$$

Three tectonic regimes can be considered depending on the horizontal loading condition (Figure 2a): (1) lithostatic, when $\Delta \sigma_{x}=0$; (2) compression, when $\Delta \sigma_{x}>0$; (3) extension, when $\Delta \sigma_{x}<0$. Equations describing the stress state for these three tectonic regimes are presented in Figure $2 \mathrm{~b}$. Note that the stress state described by the model is point-wize in essence. When applying the model to data, it is up to the researcher to estimate whether the pressure data is representative of the regional or local stress state.

\subsubsection{Deformation}

The magnitude of the deformation is proportional to $\Delta \sigma_{x}$, and the direction of maximum stretch is parallel to the direction of $\sigma_{3}$. Thus, there is no deformation in the lithostatic case, and the maximum stretch is horizontal in the extensional case and vertical in the compressional case. The total stress in the $y$-direction is always $\sigma_{y}=\sigma_{2}$, and we use the variable $\alpha$ that ranges between 0 and 1 to describe $\sigma_{2}$ as a function of $\sigma_{1}$ and $\sigma_{3}$ such that:

$$
\sigma_{2}=\alpha \sigma_{1}+(1-\alpha) \sigma_{3}
$$

Figure 2c shows how $\alpha$ is related to the mode of deformation. When $\alpha=0, \sigma_{2}=\sigma_{3}$ (see Equation 4 ), and the rock deforms by flattening. When $\alpha=1, \sigma_{2}=\sigma_{1}$, and the rock deforms by constriction. When $\alpha=0.5, \sigma_{2}=$ $\left(\sigma_{1}+\sigma_{3}\right) / 2=P$, and the deformation is plane strain.

\subsubsection{Pressure}

By definition, pressure $(P)$ corresponds to the isotropic part of the stress tensor and, in principal stress coordinates, it can be expressed as follows:

$$
P=\frac{\sigma_{1}+\sigma_{2}+\sigma_{3}}{3}
$$

Hence, $P=\sigma_{z}$ in the lithostatic case, $P<\sigma_{z}$ in extension (because $\Delta \sigma_{x}<0$ ), and $P>\sigma_{z}$ in compression (because $\Delta \sigma_{x}>0$ ). The Mohr diagrams in Figure 2d illustrate these relationships. In the diagrams, the horizontal and vertical axes represent the normal stress $\sigma_{n}$ and shear stress $\tau$ on planes within the rock mass, respectively. Pressure is represented by a cross symbol, where the central vertical bar represents the value of pressure when the rock deforms under plane-strain conditions $(\alpha=1 / 2)$ and the horizontal bar represents the range of pressure associated with values of $\alpha$ between 0 (flattening) and 1 (constriction). The equation for $P$ as a function of $\alpha$ is obtained by substituting Equation 4 into Equation 5, which yields

$$
P=\frac{(1+\alpha)}{3} \sigma_{1}+\frac{(2-\alpha)}{3} \sigma_{3}
$$

\subsubsection{Limit of Stress and Rock Failure}

When tectonic loading is applied, rocks first undergo (visco-)elastic. Stress loading can be increased up to the point where the rock breaks. At this point, the maximum stresses on a given plane within the rock are given by the Mohr-Coulomb law. If we ignore the cohesion in rocks the Mohr-Coulomb becomes 


$$
\tau=\tan \phi \sigma_{n}
$$

which is consistent with Byerlee (1978), and where $\phi$ is the friction angle. Rock experiments show that $\phi \approx 30^{\circ}$ for most rock types (Byerlee, 1978). To simplify the derivation, we ignore cohesion since it is small (order of $10-50 \mathrm{MPa}$ ) compared to the pressure of metamorphic rocks considered here (order of GPa). The supporting information (S2-S10) also allow the reader to reproduce most figures in this publication while taking cohesion into account (see Yamato and Brun (2017) for the derivation). Mohr's circle is defined by

$$
\sigma_{n}=\frac{\sigma_{1}+\sigma_{3}}{2}-\frac{\sigma_{1}-\sigma_{3}}{2} \sin \phi
$$

and

$$
\tau=\frac{\sigma_{1}-\sigma_{3}}{2} \cos \phi
$$

Substituting Equations 8 and 9 into Equation 7 yields

$$
\begin{gathered}
\sigma_{1}=\Phi \sigma_{3}, \text { with } \\
\Phi=\frac{1+\sin \phi}{1-\sin \phi} .
\end{gathered}
$$

Figure 2e illustrates the possible stress states associated with different tectonic regimes. This figure presents the whole range of possibilities from the "lithostatic" case to the brittle case.

In extension, $\sigma_{x}=\sigma_{3}$, and $\sigma_{z}=\sigma_{1}$; therefore, the minimum total horizontal stress is $\min \left(\sigma_{x}\right)=\sigma_{z} / \Phi$ (Figure 2e, middle panel). Conversely, in compression, $\sigma_{x}=\sigma_{1}$, and $\sigma_{z}=\sigma_{3}$; therefore, the maximum total horizontal stress is $\max \left(\sigma_{x}\right)=\Phi \sigma_{z}$ (Figure 2e, right panel). The quantity $\left(\sigma_{1}-\sigma_{3}\right) / 2$, that is, the radius of the Mohr circle, is also called the second invariant of the deviatoric stress tensor or the "magnitude of deviatoric stresses."

\subsubsection{Summary}

Finally, Figure 2f presents a Mohr-Coulomb diagram that summarizes the discussion to this point. The diagram is presented in a non-dimensional form where the overbar indicates that a quantity is normalized by $\sigma_{z}$ (e.g., $\bar{\sigma}_{x}=\sigma_{x} / \sigma_{z}$ ). The pressure in the lithostatic case, or lithostatic pressure, is equal to $\sigma_{z}$ (i.e., the weight of the column of rocks). The nondimensional lithostatic pressure is therefore equal to $\bar{\sigma}_{z}=1$ (Figure 2f). In compression, the normalized total horizontal stress $\bar{\sigma}_{x}$ can vary from 1 (no deformation) to $\Phi$ (onset of brittle deformation), and $P>\sigma_{z}$. In extension, $\bar{\sigma}_{x}$ can vary from $1 / \Phi$ (brittle deformation) to 1 (no deformation), and $P<\sigma_{z}$. In these three cases, following Equation 5, the nondimensional pressure $\bar{P}$ can then be written as:

$$
\begin{gathered}
\bar{P}_{l}=1, \\
\bar{P}_{e}=\frac{2-\alpha}{3} \bar{\sigma}_{x}+\frac{1+\alpha}{3}, \\
\bar{P}_{c}=\frac{1+\alpha}{3} \bar{\sigma}_{x}+\frac{2-\alpha}{3},
\end{gathered}
$$

where the subscripts $c, e$, and $l$ relate to the compression, extension and lithostatic tectonic regimes, respectively (see also Figure 2f). Another useful result is obtained by solving the previous equations for $\sigma_{z}$ : 


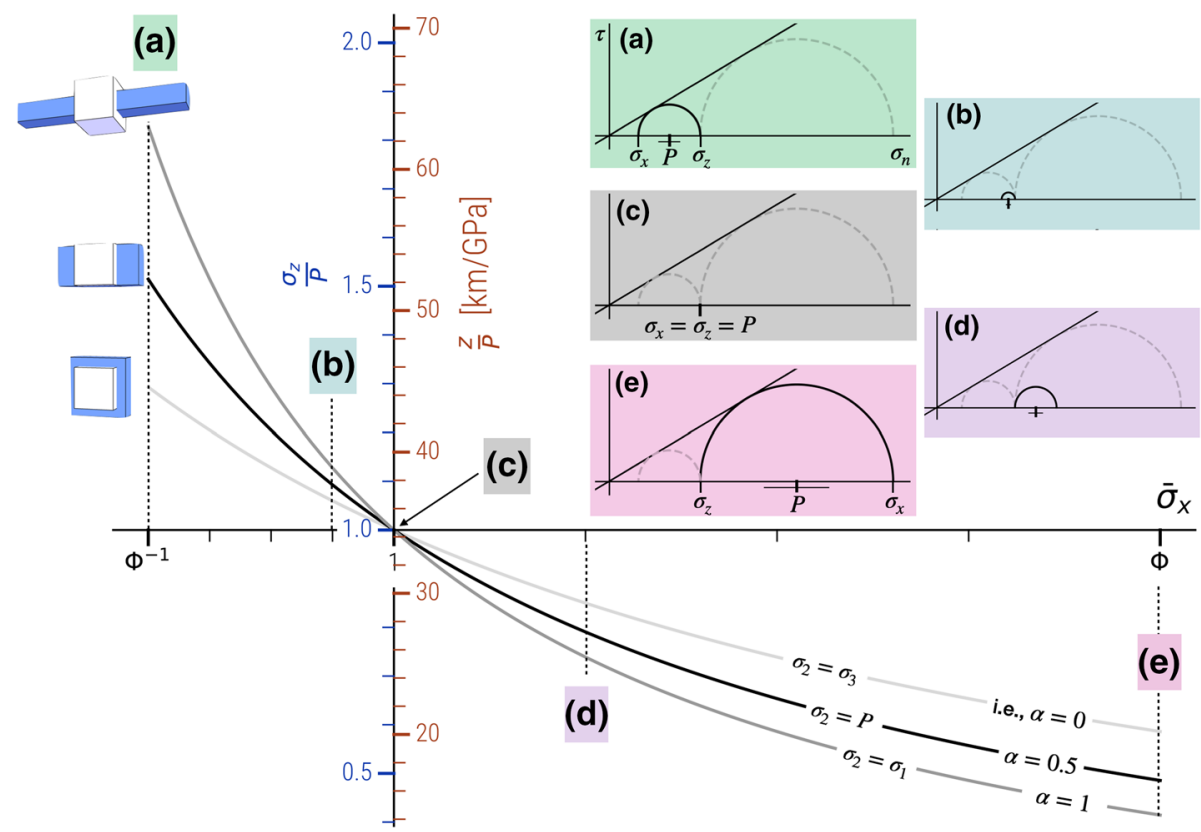

Figure 3. Pressure-to-depth conversion ratio $(z / P)$ as a function of normalized horizontal stress $\bar{\sigma}_{x}=\sigma_{x} / \sigma_{z}$. The vertical axis indicates the ratio of vertical stress to pressure $(S z / P$, blue axis) or the pressure-to-depth conversion ratio $\left(z / P\right.$, red). We use $\rho g=28,000 \mathrm{~kg} / \mathrm{m}^{2} / \mathrm{s}^{2}$, and $\tan \phi=0.65$. The three lines correspond to different values of $\alpha$ (i.e., $\left.\sigma_{2}\right)$. The mode of deformation associated with $\alpha$ is illustrated by the cartoons on the left, where the white and blue boxes represent the undeformed and deformed states, respectively. The Mohr diagrams represent the outer envelope of stress states at points a-e. In these panels, pressure $P$ is represented by a cross, as in Figure $2 \mathrm{~F}$.

$$
\left\{\begin{array}{l}
\sigma_{z}=\frac{3 P}{1+\alpha+\bar{\sigma}_{x}(2-\alpha)}, \text { when } \bar{\sigma}_{x} \leq 0, \\
\sigma_{z}=\frac{3 P}{2-\alpha+\bar{\sigma}_{x}(1+\alpha)}, \text { when } \bar{\sigma}_{x} \geq 0 .
\end{array}\right.
$$

\subsection{Pressure-to-Depth Conversion Ratio $z / P$}

To convert metamorphic pressure estimates $(P)$ into depth $(z)$, one can use the simple relation $z=\frac{z}{P} P$, where $z / P$ is the gradient of depth as a function of pressure, which we refer hereafter as the "pressure-todepth conversion ratio," expressed in $\mathrm{km} / \mathrm{GPa}$, and is equal to

$$
\begin{gathered}
\frac{z}{P}=\frac{1}{\rho g \bar{P}}, \text { where } \\
\bar{P}=P / \sigma_{z} .
\end{gathered}
$$

Figure 3 shows graphs of $1 / \bar{P}$ and $z / P$ as a function of the horizontal stresses expressed by $\bar{\sigma}_{x}$ (horizontal axis) and $\alpha$ (different lines). The graphs were calculated by substituting $\bar{P}$ in Equation 16 with Equation 13 when $\bar{\sigma}_{x} \leq 1$ (i.e., in extension) or Equation 14 when $\bar{\sigma}_{x} \geq 1$ (i.e., Panels a to e show Mohr diagrams illustrating the stress state for given values of $\bar{\sigma}_{x}$ ). Throughout this article, we use $\rho g=28,000 \mathrm{~kg} / \mathrm{m}^{2} / \mathrm{s}^{2}$, representing crustal rocks. A value of $\tan (\phi)=0.6$ is often used in the literature. This value is the result of fitting data from rock friction experiments by Byerlee (1978). In the main article, we use the value $\tan (\phi)=0.65$ that offers a better fit to the data in the absence of cohesion. The difference has only a negligible influence on pressure estimates. Readers can easily recompute our results using any value of cohesion, $\phi$, or $\rho$ by using the scripts provided in the supporting information (S2-S10). 
(a)

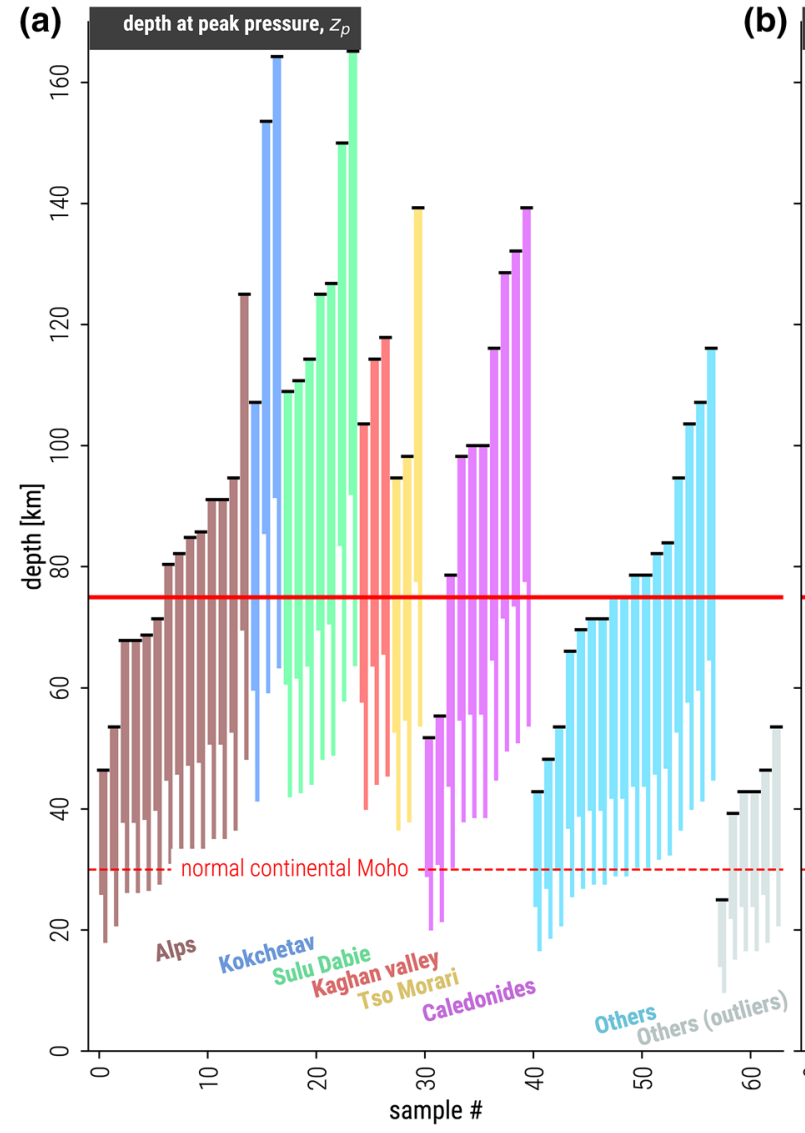

(b)

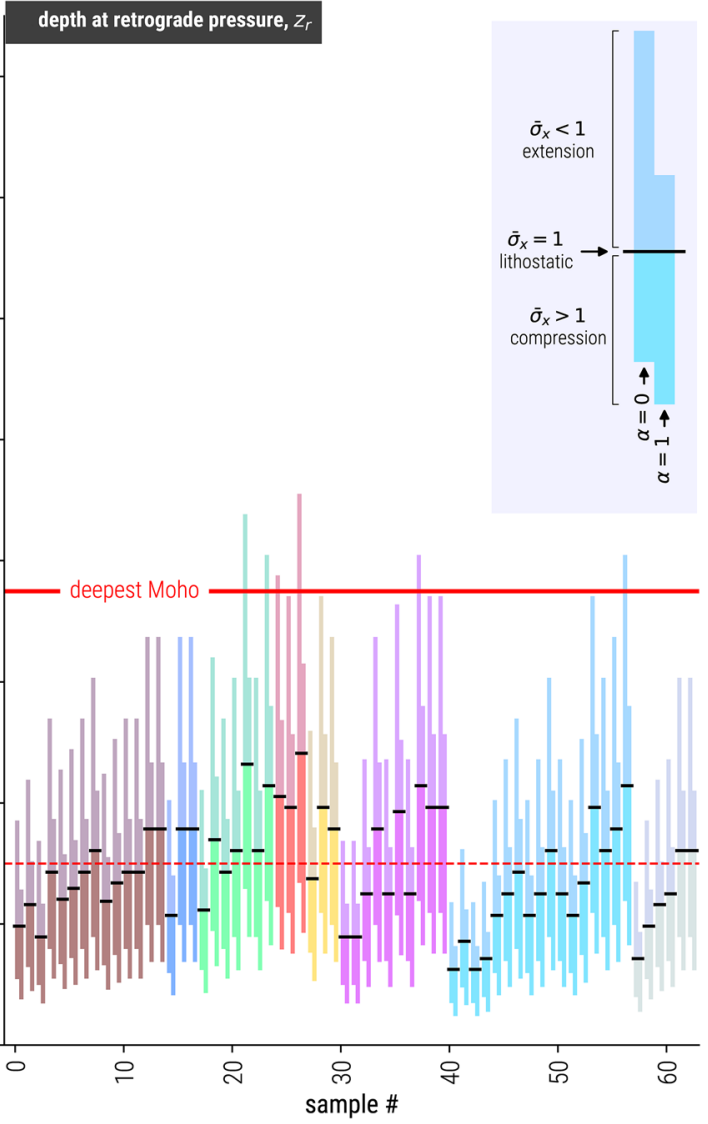

Figure 4. Depth estimates at peak pressure (a) and at retrograde pressure (b) for all samples in our data set. Colors are coded for areas. The "normal Moho" depth corresponds to the average depth of the continental Moho in regions where the crust is neither thickened nor thinned and is $30 \mathrm{~km}$. The deepest Moho $(75 \mathrm{~km})$ corresponds to the current depth of the Moho below the Tibetan Plateau. This figure can be reproduced using the computer script from supporting information S4.

When the pressure is considered lithostatic ( $\bar{\sigma}_{x}=1$, Figure 3c), the pressure-to-depth conversion ratio is $z / P=35 \mathrm{~km} / \mathrm{GPa}$. However, this ratio varies significantly when $\bar{\sigma}_{x}$ increases (compression) or decreases (extension). For example, in the case where $\sigma_{2}=\sigma_{1}$ and $\bar{\sigma}_{x}$ is minimum, $z / P=64 \mathrm{~km} / \mathrm{GPa}$ (Figure 3a). In contrast, when $\bar{\sigma}_{x}$ is maximum, $z / P=16 \mathrm{~km} / \mathrm{GPa}$ (Figure 3e). Small deviations of $\bar{\sigma}_{x}$ from 1 have significant impacts on the pressure-to-depth conversion ratio. For example, when the applied tectonic stress $\Delta \bar{\sigma}_{x}=\min \left(\Delta \bar{\sigma}_{x}\right) / 4, z / P=39 \mathrm{~km} / \mathrm{GPa}$ (Figure 3b), and when $\Delta \bar{\sigma}_{x}=\max \left(\Delta \bar{\sigma}_{x}\right) / 4, z / P=25 \mathrm{~km} / \mathrm{GPa}(\mathrm{Fig}-$ ure 3d). The value of $\alpha$ also exerts a strong control on the pressure-to-depth conversion ratio, particularly in extension; e.g., when $\bar{\sigma}_{x}=\Phi^{-1}$, the conversion ratio varies from 45 to $64 \mathrm{~km} / \mathrm{GPa}$ depending on the value of $\alpha$.

\subsection{Application of the One-Point Method}

We now apply the pressure-to-depth conversion ratio derived in the previous section to our data set of peak $\left(P_{p}\right)$ and retrograde $\left(P_{r}\right)$ metamorphic pressures. Figure 4 shows the depths estimated from this conversion. Depth estimates at peak pressure $\left(z_{p}\right)$ are shown only for compressive stress states (Figure 4a), while depth estimates at retrograde pressure $\left(z_{r}\right)$ are shown for both compressive and extensional stress states (Figure 4b). We indicate two reference depths: (a) $30 \mathrm{~km}$ (red dashed line), which is the depth of a "normal continental Moho" defined as the thickness of an isostatically balanced continental crust with topography at sea level, and (b) $75 \mathrm{~km}$ (thick red line), which is the depth of the Moho below the Tibetan Plateau and is the present-day "deepest Moho" on Earth. For each sample, the black horizontal bar indicates the lithostatic pressure case. The two columns for each sample indicate the two extreme deformation regimes: flattening $\left(\alpha=0\right.$, or $\left.\sigma_{2}=\sigma_{3}\right)$ and constriction $\left(\alpha=1\right.$, or $\left.\sigma_{2}=\sigma_{1}\right)$. 
At peak pressure conditions, the upper estimate of depth $z_{p}$ (Figure 4a, black bars) corresponds to lithostatic conditions (i.e., with no deformation), with a conversion ratio $z / P=35 \mathrm{~km} / \mathrm{GPa}$ (Figures $4 \mathrm{a}$ and $3 \mathrm{c}$ ). Under this condition, $z_{p}$ values are $\sim 165 \mathrm{~km}$ for samples from the Kokchetav and Sulu-Dabie regions, $140 \mathrm{~km}$ for the Tso Morari and Caledonides, and $120 \mathrm{~km}$ for the Alps and Kaghan valley. The minimum estimate of $z_{p}$ results from assuming constricting deformation at brittle failure under compression (i.e., $\alpha=1$ and $\bar{\sigma}_{x}=\Phi$ ). The conversion ratio is then $z / P=16 \mathrm{~km} / \mathrm{GPa}$ (Figure $3 \mathrm{e}$ ) and $z_{p}<75 \mathrm{~km}$ for all samples, that is, shallower than the present-day deepest Moho on Earth. The uncertainty range for $z_{p}$ for a single data point varies from $\approx 15 \mathrm{~km}$ for sample \#40 to $\approx 100 \mathrm{~km}$ for samples \#16 and \#23.

Under retrograde conditions, the lithostatic case represents an intermediate estimate because we consider both compressive and extensive tectonic regimes (Figure 4b). The upper estimate for $z_{r}$ results from assuming flattening deformation at brittle failure in extension (i.e., $\alpha=0$ and $\bar{\sigma}_{x}=1 / \Phi$ ). The conversion ratio is then $z / P=64 \mathrm{~km} / \mathrm{GPa}$ (Figure 3a). A few samples from the Alps have a maximum depth estimate of $z_{r}>85 \mathrm{~km}$. For samples from the Kokchetav and Sulu-Dabie orogens, $z_{r}=75 \mathrm{~km}$, and $z_{r}=50 \mathrm{~km}$ for samples from the Kaghan valley, Tso Morari and Caledonides. The minimum estimate of $z_{r}$ results from assuming constricting deformation at brittle failure in compression (i.e., $\alpha=1$ and $\bar{\sigma}_{x}=\Phi$ ). $z_{r}$ can be as shallow as 10-20 km for all samples. The uncertainty range on the estimate of $z_{r}$ for a single data point is up to $70 \mathrm{~km}$ for sample \#11 whose maximum depth is $\approx 90 \mathrm{~km}$. All samples have at least part of their range shallower than the deepest present-day Moho at both peak and retrograde pressures.

Figure 5a shows the estimated exhumation calculated as the difference between $z_{p}$ and $z_{r}$. We present six special cases involving different values of $\bar{\sigma}_{x}^{p}, \bar{\sigma}_{x}^{r}, \alpha_{r}$, and $\alpha_{r}$ to illustrate the dependence of the estimated exhumation on the stress state. In Figures $5 \mathrm{c}-5 \mathrm{~h}$, we present Mohr diagrams for these six cases calculated using $P_{p}$ and $P_{r}$ from a reference sample.

The maximum exhumation is predicted when $P_{p}$ corresponds to lithostatic pressure and $P_{r}$ is recorded at brittle failure in compression (Figure 5a, top of color bars, and Figure 5c). The maximum predicted exhumation in our data set varies between 20 and $150 \mathrm{~km}$.

We use the term "always lithostatic" for the case where both $P_{p}$ and $P_{r}$ are lithostatic pressures. This case is shown with black horizontal bars in Figures $5 \mathrm{a}$ and $5 \mathrm{~b}$ and illustrated in Figure $5 \mathrm{~d}$. In this case, exhumation varies between 25 and $125 \mathrm{~km}$ for our data set. Since the "always lithostatic" case is the most commonly used solution in the literature, we use it as a reference to normalize the results. The normalized graph (Figure 5b) allows us to express the exhumation amount as a percentage of a reference case and outline similarities between samples.

The red rectangle symbol Figures ( $5 \mathrm{a}$ and $5 \mathrm{~b}$ ) corresponds to a case where deformation is compressive for $P_{p}$ and extensive for $P_{r}$, the magnitude of deviatoric stress is a quarter of the maximum value, and deformation is plane strain (Figure 5e). This stress state represents a conservative estimate for rocks that deform by viscous deformation at depth. This low-deviatoric stress has a significant impact on the quantity of exhumation: on average, this case results in an estimate of exhumation that is, only $60 \%$ of that for the "always lithostatic" case (see red line in Figure 5b). The blue rectangle symbol (Figures 5a and 5b) represents a case of intermediate stress where the magnitude of deviatoric stress is half of the maximum value (Figure 5f). On average, this case's results are 35\% of the estimate for the "always lithostatic" case (see red line in Figure $5 \mathrm{~b}$ ). The dark yellow rectangles indicate the scenario where deformation is brittle in compression at peak pressure, and $P_{r}$ corresponds to lithostatic pressure under plane strain deformation. This scenario predicts at most $30 \mathrm{~km}$ of exhumation and a minimum of $-10 \mathrm{~km}$ (i.e., $10 \mathrm{~km}$ of additional burial). In this case, the predicted exhumation is $\approx 10 \%$ of that for the "always lithostatic" case, on average. The minimum exhumation estimate is obtained when deformation is brittle and constrictive in compression for $P_{p}$, and deformation is brittle in extension and occurs by flattening for $P_{r}$. The minimum exhumation estimate is between 0 and $-50 \mathrm{~km}$.

For most samples, the normalized amount of exhumation for a specific case, for example, low stress (red rectangles), is contained within a small range around an average value. However, the samples from the category "Others (outliers)" have significantly different values. Although their values of $P_{p}$ and $P_{r}$ are not anomalous (e.g., Figure 1), their combination clearly differs from other samples (see Figure 1c). The relatively low dispersion of exhumation is related to the apparent proportionality between $P_{p}$ and $P_{r}$ (see Figure 1c). 
(a)

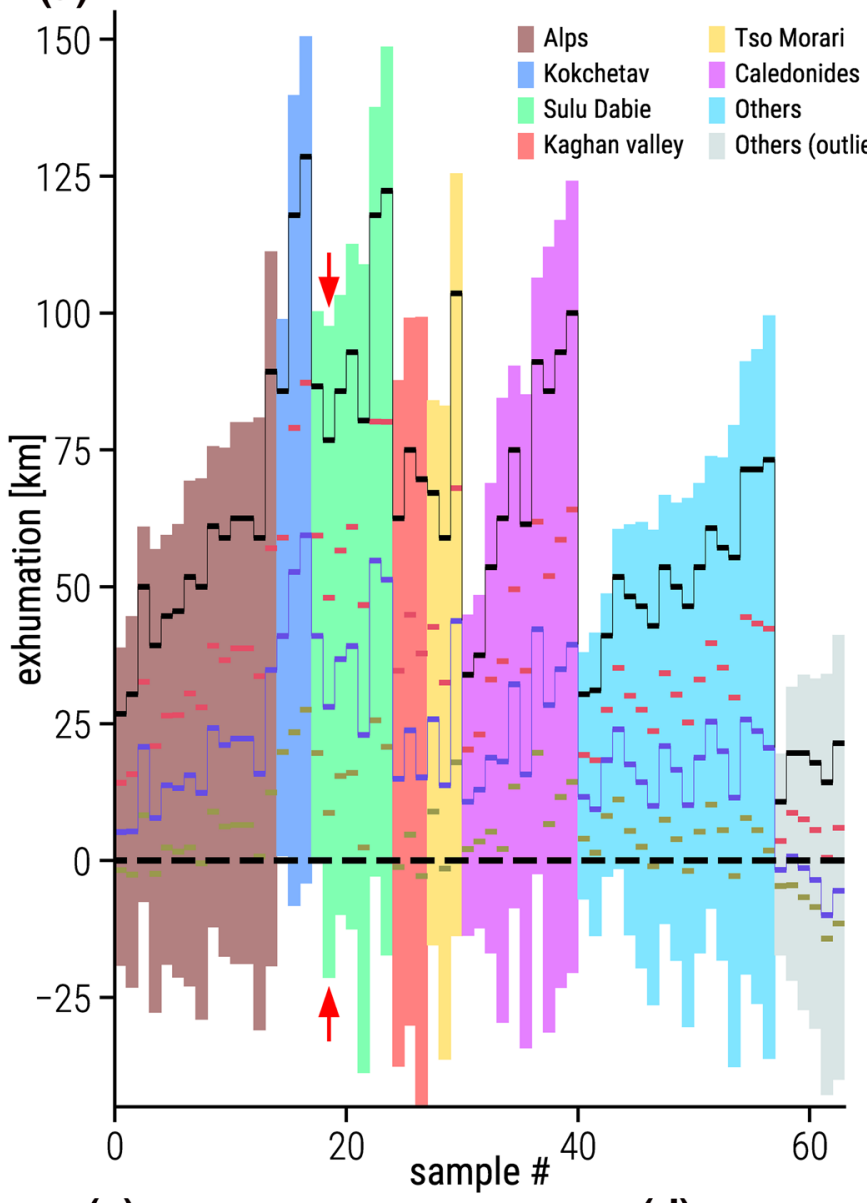

(c)

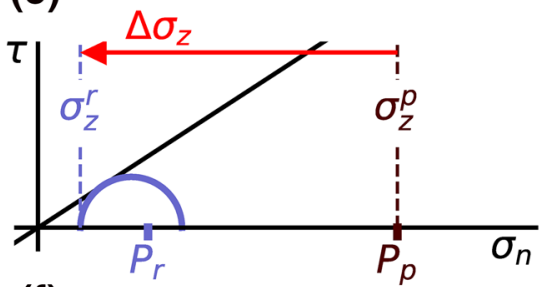

(f)

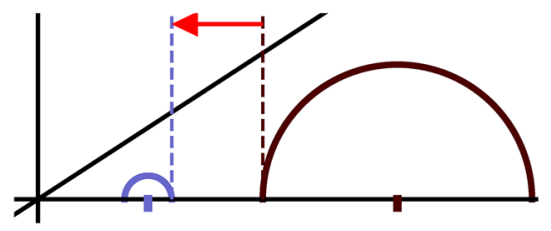

(d)

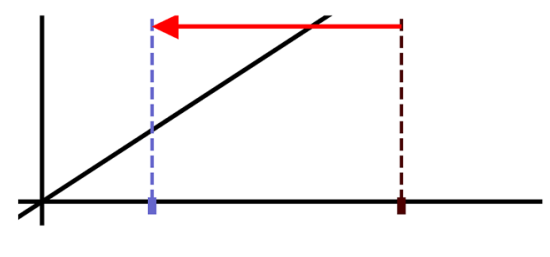

(g)

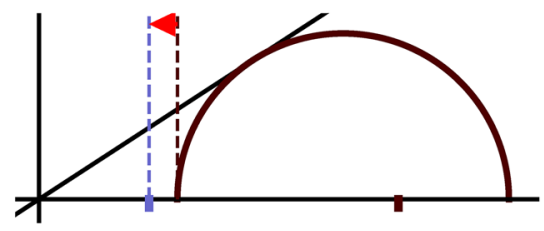

(b)

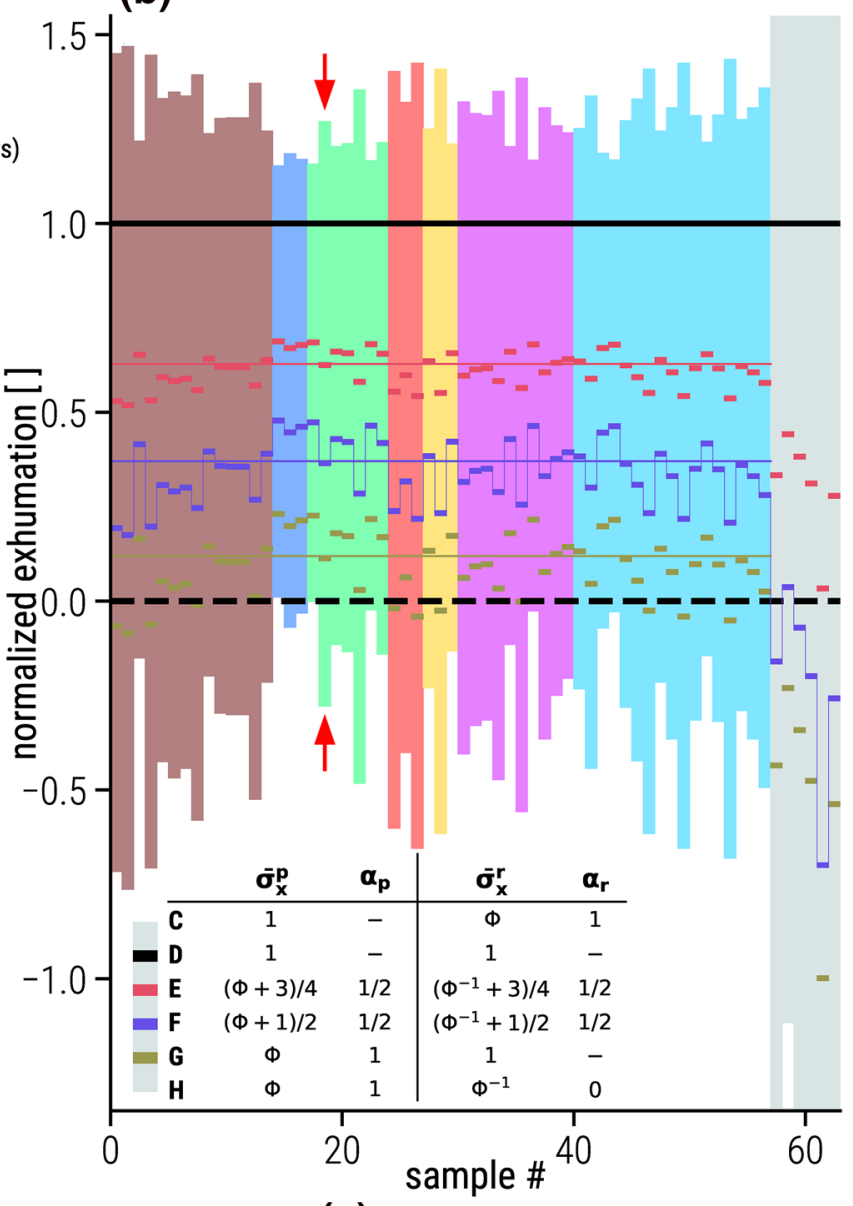

(e)

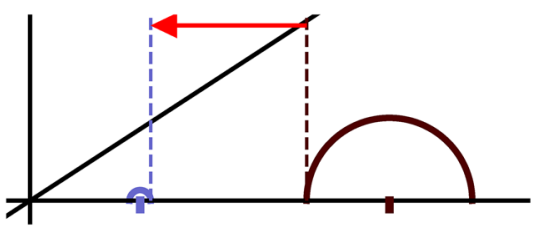

(h)

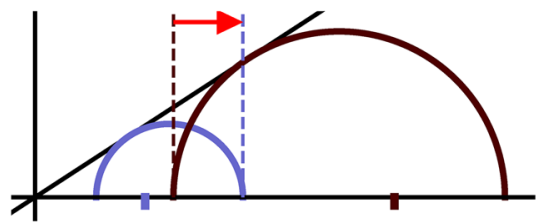

Figure 5. (a) Estimated amount of exhumation calculated as the difference between the estimated depth at peak and retrograde pressures $\left(z_{p}-z_{r}\right)$ for all samples from our data set. Bar colors indicate the provenance. (b) Same as (a) but normalized by the amount of exhumation obtained by considering $P_{p}$ and $P_{r}$ as lithostatic pressures (i.e., "always lithostatic" case). We calculated six special cases by combining different values of $\bar{\sigma}_{x}^{p}, \bar{\sigma}_{x}^{r}, \alpha_{p}, \alpha_{r}$, that is, maximum and minimum exhumation, and four intermediate cases (colored rectangles). The values used are shown in the table inset in (b). (c-h) Mohr diagrams for the six special cases using $P_{p}, P_{r}$ from a reference sample indicated by red arrows in (a and b). The characteristics of the special cases are (c) maximum exhumation case, (d) "always lithostatic" case, (e-f) cases with moderate deviatoric stress, (g) exhumation amount close to zero, and (h) minimum exhumation (negative exhumation, i.e., burial). This figure can be reproduced using the computer script from supporting information S5. 
In this section, we show that the transition from $P_{p}$ to $P_{r}$ can be interpreted as the result of exhumation from great depth (Figures $5 \mathrm{c}$ and $5 \mathrm{~d}$ ). The data are also compatible with an opposite interpretation: that this transition is the result of a change in stress state while depth is constant (Figure $5 \mathrm{~g}$ ) or even while burial continues (Figure 5h).

\section{Two-Point Method of Pressure-to-Depth Conversion}

In this section, we re-examine our data set with the additional constraint that $z_{p}=z_{r}$. In this way, we can use $P_{p}$ and $P_{r}$ together to reduce the uncertainty range for the depth estimate. We call this method "two-point pressure-to-depth conversion." In the case of a homogeneous rock and ignoring the possible role of fluids, the stress state can be modified in only two ways: (1) by modifying the magnitude of the horizontal stress or (2) by rotating the stress field. We explore these mechanisms independently, as well as a special case, in the following sections.

\subsection{Mechanism 1: Change in the Magnitude of Horizontal Stress (S-model 1)}

First, we consider the change in pressure triggered by a change in the magnitude of the horizontal stress $\left(\bar{\sigma}_{x}\right)$. Figure 6a shows five Mohr circles constructed with various values of $\bar{\sigma}_{x}$. Note that the Mohr circle with $\bar{\sigma}_{x}=1$ is a point. In Figures $6 \mathrm{~b}-6 \mathrm{j}$, we represent our data set as colored circles in the $P_{p}$ versus $P_{r}$ space. These data points are placed on top of a colored contour map of $\bar{\sigma}_{x}^{r}$ computed for given values of $P_{p}, P_{r}, \bar{\sigma}_{x}^{p}, \alpha_{p}, \alpha_{r}$, where subscripts or overscripts $p$ and $r$ refer to the peak and retrograde stages, respectively. The values used are indicated at the top of columns and the beginning of rows of panels. A contour map of $z=z_{p}=z_{r}$ is also shown (black horizontal lines). The range of values calculated for $\bar{\sigma}_{x}^{r}$ covers stress states that do not exceed the Coulomb failure criterion. Gray areas correspond to areas where $\bar{\sigma}_{x}^{r}$ has no meaningful solution (i.e., because the stress magnitude would exceed the brittle yield stress). This means that the model cannot explain data plotting in the gray area. In contrast, when a data point is on top of the colored contour map, the combination of $P_{p}, P_{r}$ for this data point can be obtained using Equations 13-16, the combination of $\bar{\sigma}_{x}^{p}, \alpha_{p}, \alpha_{r}$ given and the value of $\bar{\sigma}_{x}^{r}$ and $z$ shown by the contour map.

When the stress state is lithostatic at peak conditions, that is, $\bar{\sigma}_{x}^{p}=1$, only outliers plot in the solution domain (Figures 6b-6d), which means that the transition from $P_{p}$ to $P_{r}$ observed in the data cannot be explained only by increasing or decreasing the horizontal stress at constant depth if the stress state is lithostatic under peak conditions. When the initial horizontal stress is $\bar{\sigma}_{x}^{p}=(1+\Phi) / 2$, a few data points lie in the solution domain for the combinations $\alpha_{p}=0, \alpha_{r}=1$ (Figure 6e) and $\alpha_{p}=\alpha_{r}=1 / 2$ (Figure 6f). However, approximately half of the points lie in the solution domain when $\alpha_{p}=1, \alpha_{r}=0$ (Figure $6 \mathrm{~g}$ ). Outliers can be explained by $\bar{\sigma}_{x}^{r}>1$ (i.e., compressive stress state), while other points are explained by $\bar{\sigma}_{x}^{r}<1$ (i.e., extensional stress state, Figure $6 \mathrm{~g}$ ). When the initial horizontal stress is $\bar{\sigma}_{x}^{p}=\Phi$ (i.e., brittle deformation), few data points lie in the solution domain for the combinations $\alpha_{p}=0, \alpha_{r}=1$ (Figure 6h). When $\alpha_{p}=\alpha_{r}=1 / 2$, half the points lie in the solution and these points correspond to values of $\bar{\sigma}_{x}^{r}<1$ (except for outliers, Figure 6i). When $\alpha_{p}=1, \alpha_{r}=0$, all the points have a solution (Figure $6 \mathrm{j}$ ). Most points have $\bar{\sigma}_{x}^{r}<1$, but a few points are also associated with small values $\bar{\sigma}_{x}^{r}>1$. Outliers are characterized by high values of $\bar{\sigma}_{x}^{r}$.

In all models except the one in Figure $6 \mathrm{j}$, some data points have a higher $P_{p}$ than acceptable within the model bounds. On the other hand, there is no data point with $P_{p}$ lower (or $P_{r}$ higher) than that predicted by the model. The outlier points also plot within the bounds of the model. Overall, each data point is within the model boundaries or close to its boundary on at least one graph (e.g., Figure 6j). Therefore, the model where the transition from $P_{p}$ to $P_{r}$ is triggered by a change in the stress state at constant depth $\left(z_{p}=z_{r}\right)$ explains the data. While some points lie within the model boundaries only for a deviatoric stress with a large magnitude, other points can be explained by a change in stress with only moderate deviatoric stresses (Figure $6 \mathrm{~g}$ ). Values of $\alpha_{p}, \alpha_{r}$ are also important to explain the data; for example, some data points can be explained only when $\alpha_{p}=1, \alpha_{r}=0$. For these data points, the model predicts a change in the mode of deformation from constriction to flattening during the transition from $P_{p}$ to $P_{r}$. Therefore, analyses of the mode of deformation in metamorphic rock samples provide a way to validate or falsify our model.

We compute the depth depending on the given value of $\bar{\sigma}_{x}^{p}$ and $\alpha_{p}$ from Equations 14 and 16. For $\bar{\sigma}_{x} \geq 1$, the pressure-to-depth conversion ratio increases with decreases in both $\bar{\sigma}_{x}$ and $\alpha$ (see Figure 3). Graphically, 

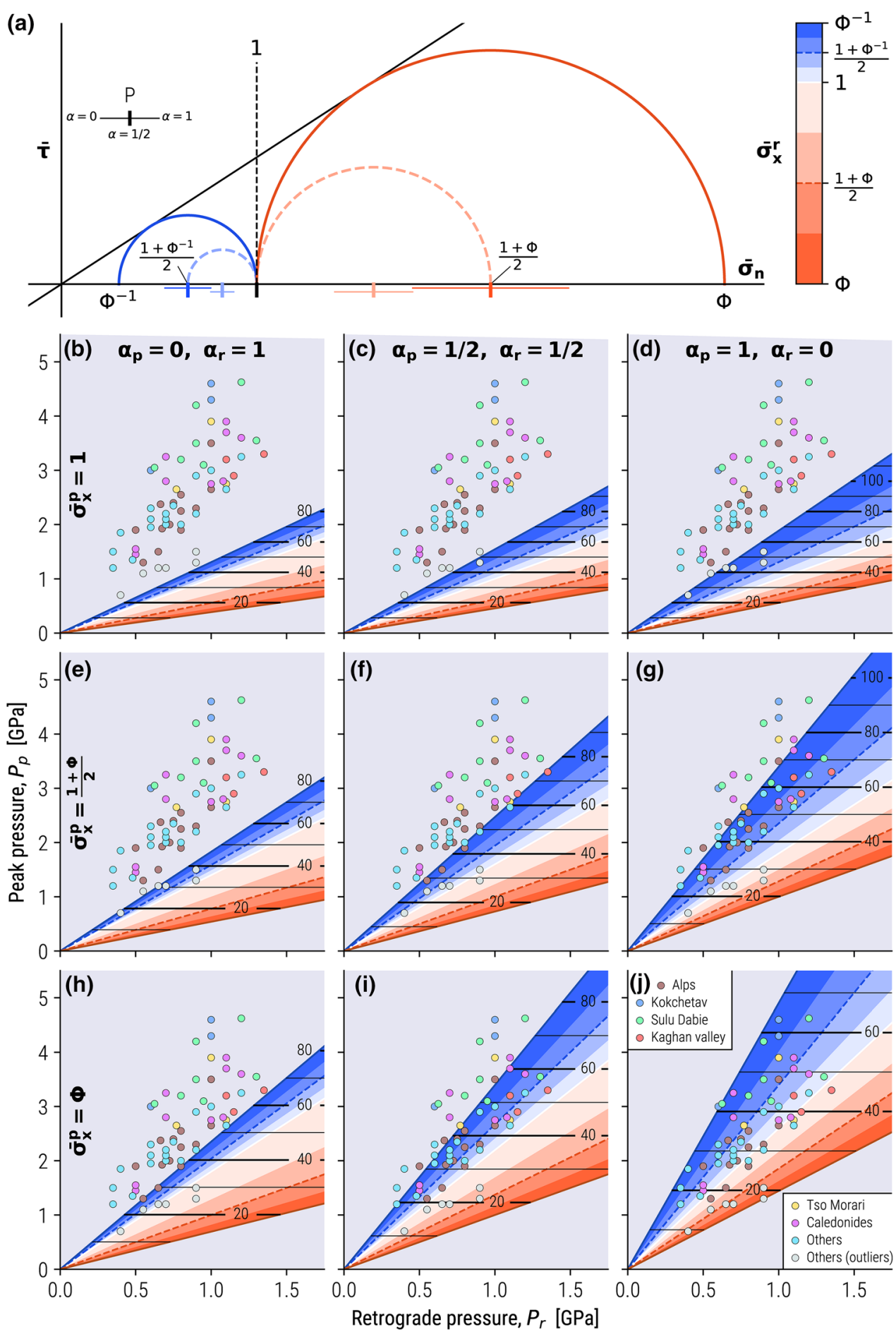

Figure 6. Results for the horizontal stress change-driven model. (a) A Mohr diagram illustrating the stress states associated with different values of $\bar{\sigma}_{x}$. The normal stress (horizontal axis) and shear stress (vertical axis) are normalized by $\sigma_{z}$. (b-j) Peak pressure as a function of retrograde pressure for data (colored circles) and model (colored contour plot). The estimated depths, in km, for each model are indicated by black contour lines. Gray areas indicate zones where the model does not have a solution (i.e., the deviatoric stress would exceed the yield stress). The model peak pressure is calculated from Equation 16 with parameters $\rho g=28,000 \mathrm{~kg} / \mathrm{m}^{2} / \mathrm{s}, \tan (\phi)=0.65, \bar{\sigma}_{x}=\bar{\sigma}_{x}^{p}, \alpha=\alpha^{p}$. The model retrograde pressure uses $\bar{\sigma}_{x}^{r}, \alpha^{r}$. Each panel in a row uses the value of $\bar{\sigma}_{x}^{p}$ indicated in the leftmost panel of the row. Each panel in a column uses the values of $\alpha^{p}$ and $\alpha^{r}$ indicated at the top of the column. This figure can be reproduced using the computer script from supporting information S6. 
this is expressed as the spacing between depth contours widening toward the right (e.g., from 6B to D) and bottom panels (e.g., from $6 \mathrm{~B}$ to $\mathrm{H}$ ). The cases where $\bar{\sigma}_{x}^{p}=1$ provide the highest pressure-to-depth conversion, but only outliers lie within the solution domain. Their maximum depth is $\sim 55 \mathrm{~km}$ (Figure $6 \mathrm{~d}$ ). The deepest depth estimates, $\sim 75 \mathrm{~km}$, are obtained when $\bar{\sigma}_{x}^{p}=(1+\Phi) / 2$ (Figures $6 \mathrm{f}$ and $6 \mathrm{~g}$ ). In the case where $\bar{\sigma}_{x}^{p}=\Phi$, many points lie in the solution range, but a low pressure-to-depth conversion ratio limits the depth. Thus, the maximum depth is $\sim 65 \mathrm{~km}$ (Figures $6 \mathrm{i}$ and $6 \mathrm{j}$ ). We discuss depth estimates in detail in Section 3.4 .

\subsection{Mechanism 2: Stress Rotation (S-model 2)}

We now consider the change in pressure triggered by a rotation of the stress field. We assume that when the rock records $P_{p}$, the vertical and horizontal directions are principal stress directions, as in the previous sections. Then, the stress field rotates by an angle $\theta$ around axis $y$, and the rock records $P_{r}$. Figure 7a shows Mohr circles with five different values of $\theta$.

Graphically, when we apply a rotation to a stress state where $\sigma_{1}$ is initially horizontal (i.e., compressional tectonic regime), the Mohr circle is shifted to the left (Figure 7a). The maximum shift corresponds to $\theta=90^{\circ}$, and $\sigma_{1}$ is vertical (i.e., extensional tectonic regime). Eventually, the Mohr circle may become tangent to the Coulomb yield envelope. Since the model does not admit stress states beyond this envelope, the radius of the Mohr circle has to decrease upon further rotation to remain tangent to it (see Figure $7 \mathrm{a}, \theta \geq 45^{\circ}$ ).

To formalize this behavior mathematically, we first define the yield function for Mohr-Coulomb plasticity:

$$
F=\frac{\sigma_{1}-\sigma_{3}}{2}-\frac{\sigma_{1}+\sigma_{3}}{2} \sin \phi
$$

Then, the principal stresses $\sigma_{1}$ and $\sigma_{3}$ as a function of $\theta$ are expressed as

$$
\begin{gathered}
\text { when } F<0,\left\{\begin{array}{r}
\sigma_{3}=\sigma_{z}\left(1+\left(\bar{\sigma}_{x}^{p}-1\right) \frac{\cos 2 \theta-1}{2}\right), \\
\sigma_{1}=\sigma_{z}+\tau_{I I}(\cos 2 \theta+1),
\end{array}\right. \\
\text { when } F=0,\left\{\begin{array}{c}
\sigma_{3}=\frac{2 \sigma_{z}}{1+\Phi-\frac{\Phi-1}{\cos 2 \theta}} \\
\sigma_{1}=\Phi \sigma_{3} .
\end{array}\right.
\end{gathered}
$$

Note that the first equation is only valid for $\bar{\sigma}_{x}^{p} \geq 1 \sigma_{2}$ is calculated using Equation $4, P_{p}$ is the mean stress for $\theta=0$, and $P_{r}$ is the mean stress for a given value of $\theta$.

Figures $7 \mathrm{~b}-7 \mathrm{~h}$ are constructed in the same way as Figure 6, but the brownish colored contour map now represents $\theta$.

A lithostatic stress state is isotropic. Thus, pressure remains constant upon rotation $\bar{\sigma}_{x}^{p}=\bar{\sigma}_{x}^{r}=P_{p}=P_{r}=1$ (Figure 7b). The resulting line in the $P_{p}, P_{r}$ space does not cross the data cloud, that is, does not explain the data. For stress states tangent to the Coulomb envelope, the upper limit of the contour map for $\theta\left(\theta=90^{\circ}\right)$ is the same as the upper limit of $\bar{\sigma}_{x}^{r}\left(\bar{\sigma}_{x}^{r}=1 / \Phi\right)$ (see Figure 6), while the lower limit $\left(\theta=0^{\circ}\right)$ corresponds to the case $\bar{\sigma}_{x}^{r}=\bar{\sigma}_{x}^{p}$ in the previous model. Therefore, the boundaries of the model are similar for this model (involving $\theta$ ) and for the previous model (involving $\bar{\sigma}_{x}^{r}$ ). Although extreme stress states are identical, intermediate cases are different (e.g., compare Figure 6a and Figure 7a). When $\bar{\sigma}_{x}^{p}=(1+\Phi) / 2$, a minimum of $\theta=45^{\circ}$ is required to explain the data (Figures 7c-7e). As with the previous model, all data points are consistent with a model where $\bar{\sigma}_{x}^{p}=\Phi, \alpha_{p}=1, \alpha_{r}=0$ (Figure $7 \mathrm{~h}$ ). In this case, outliers are explained by $\theta=0^{\circ}-30^{\circ}$ and other points by $\theta=30^{\circ}-90^{\circ}$. Since the depth contour map is computed based on $\bar{\sigma}_{x}^{p}, \alpha_{p}$ only and the model range is similar to the previous model, the remarks concerning depth made in Section 3.1 also apply here.

Since both this model (Figure 6) and the previous one (Figure 7) can explain the data, there is an ambiguity about which mechanism is responsible for the stress change. Once again, the predictions of this model can 
(a)

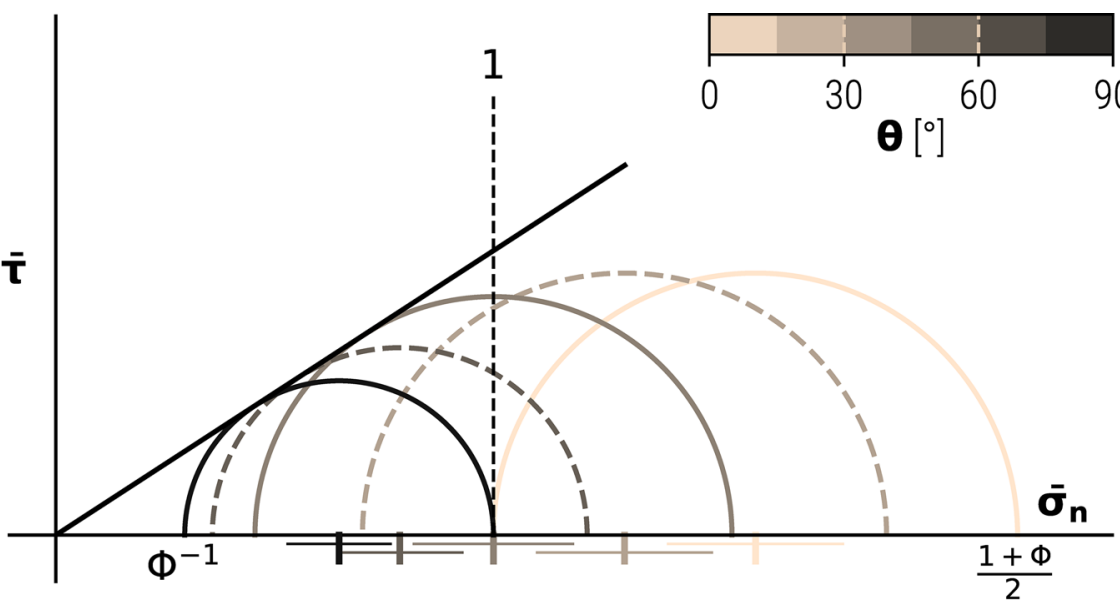

(c)

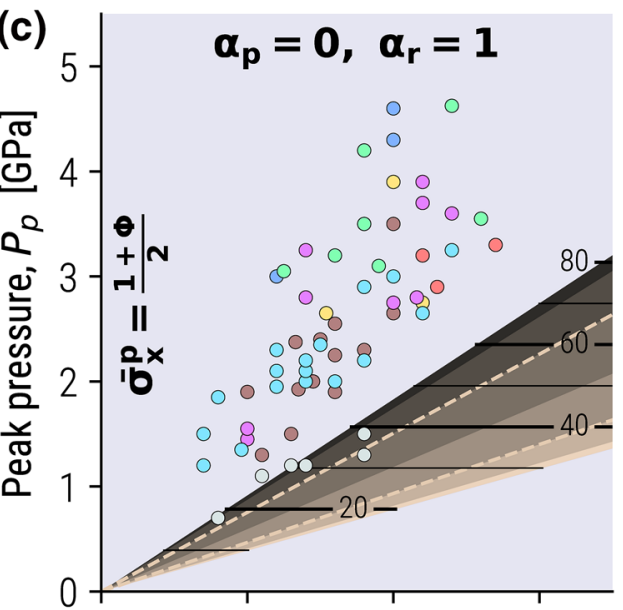

(f)

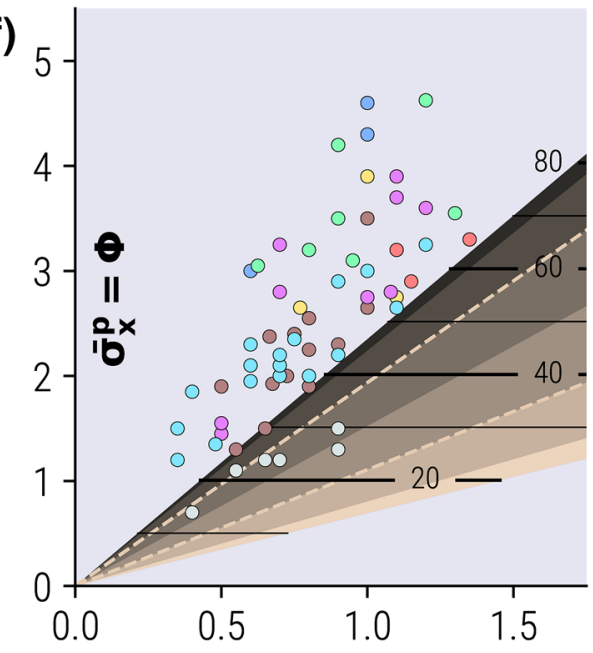

(d) $\alpha_{p}=1 / 2, \alpha_{r}=1 / 2$

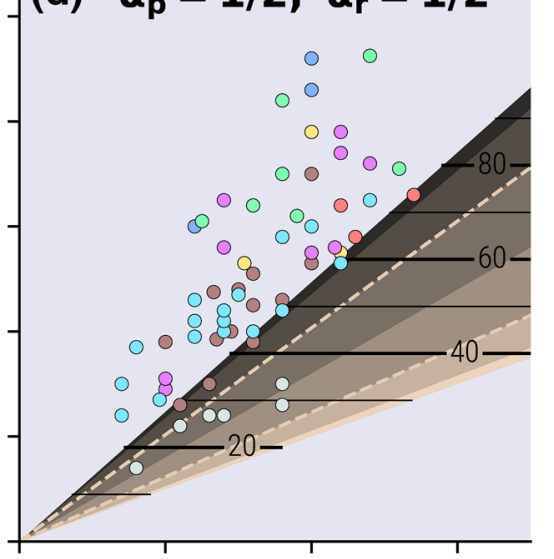

(g)

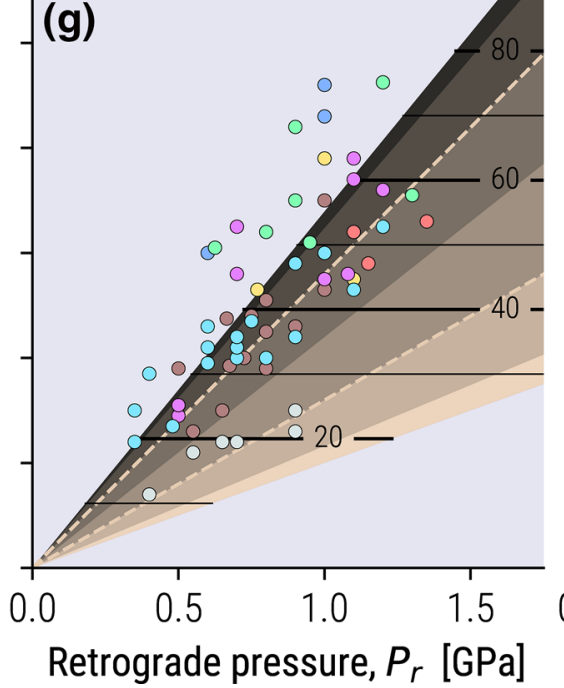

(b) $\alpha_{p}=1, \alpha_{r}=0$
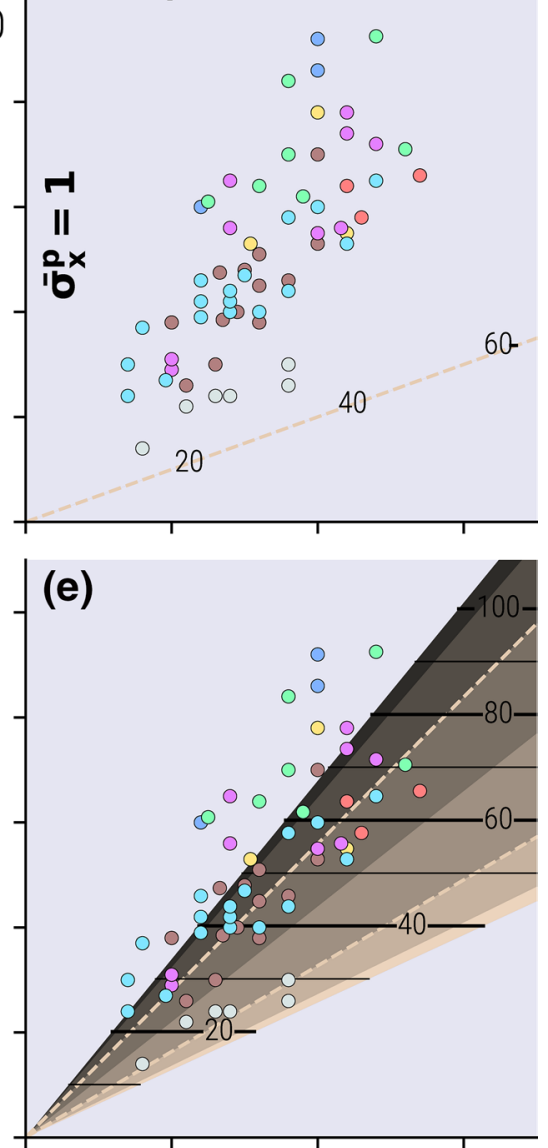

(h) Alps

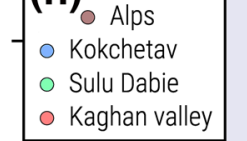

- Kaghan valley
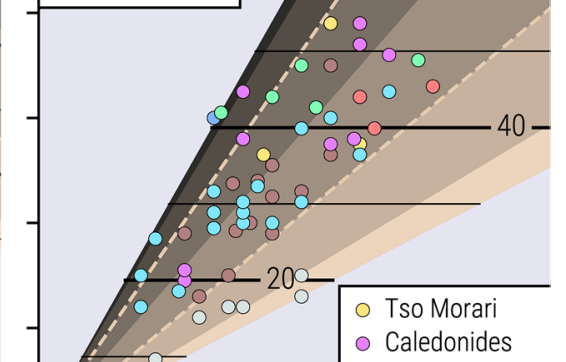

- Caledonides

- Others

O Others (outliers)

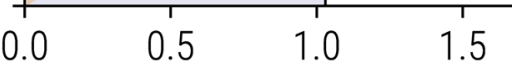

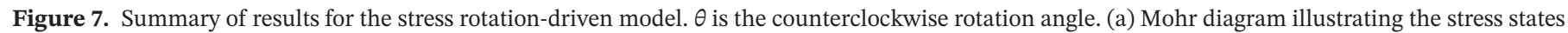

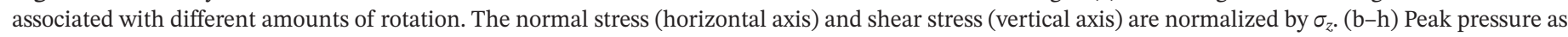

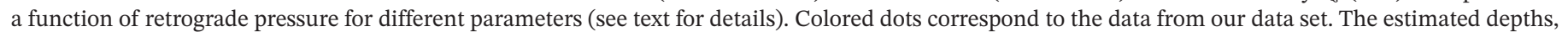
in $\mathrm{km}$, for each model are indicated by black horizontal lines. Gray areas indicate zones where the model does not have a solution. We use parameters $\rho g=28,000 \mathrm{~kg} / \mathrm{m}^{2} / \mathrm{s}$ and $\tan (\phi)=0.65$. Each panel in a row uses the value of $\bar{\sigma}_{x}^{p}$ indicated in the leftmost panel of the row. Each panel in a column uses

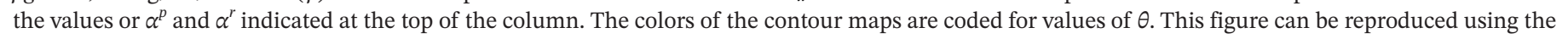
computer script from S7. 


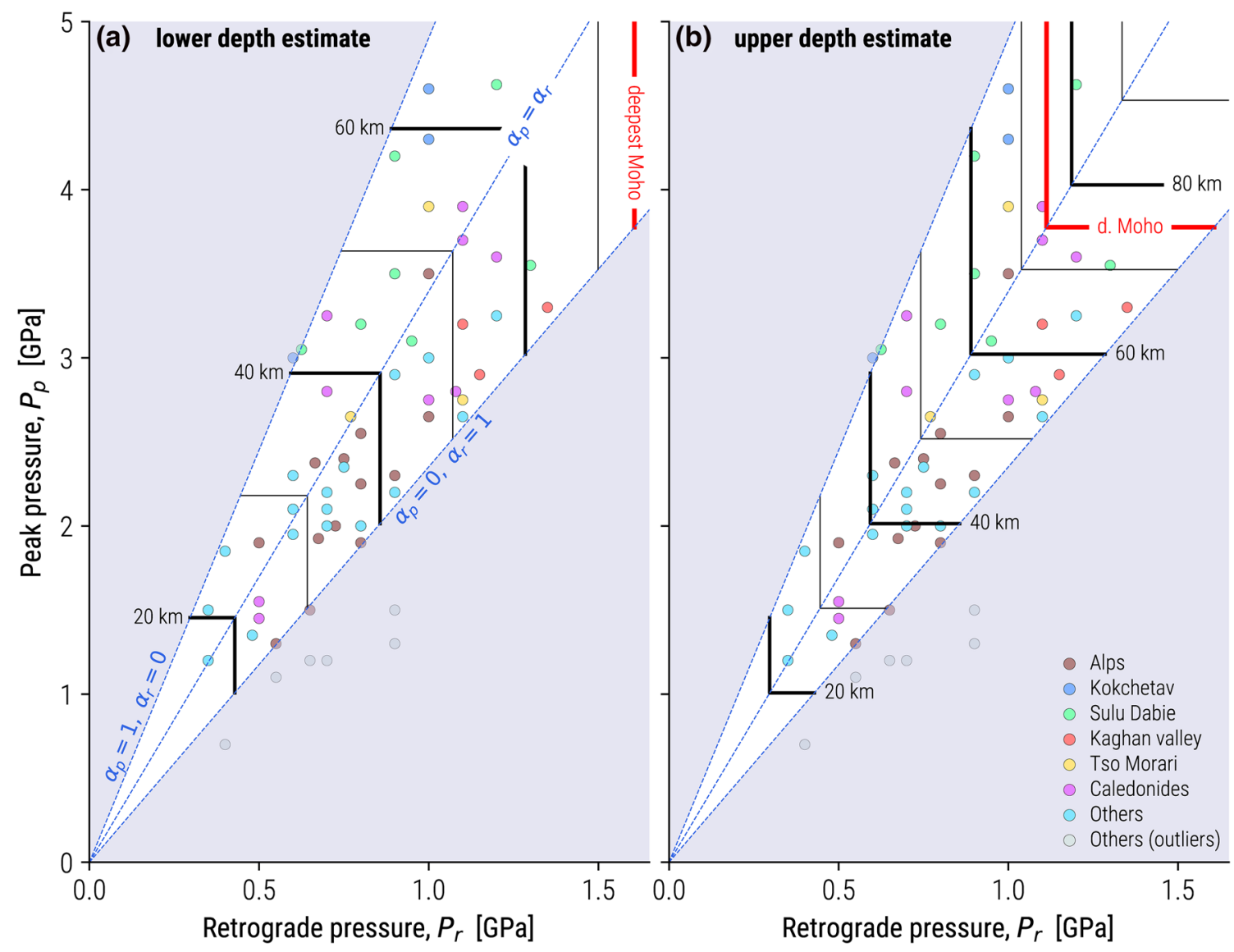

Figure 8. Data points in the $P_{p}$ versus $P_{r}$ space. Contours of depth according to (a) the lower estimate and (b) upper estimate of our model. The model has solutions within the white fan and no solution in the gray domain. The color of the data points indicates the geographic region. This figure can be reproduced using the computer script from supporting information S8.

be validated or falsified using strain data. Indeed, the rotation of the principal stress directions implies a rotation of the principal strain direction.

\subsection{A Special Case: Compression to Extension in the Brittle Limit (YB-Model)}

When $\bar{\sigma}_{x}^{p}=\Phi$, depending on the values of $\alpha_{p}, \alpha_{r}$, the solution for $\theta=90^{\circ}$ (which corresponds to the upper limit of the solution domain) can outline the lower extent of the data point cloud (Figure 7f), pass through it (Figure 7g), or outline its upper extent (Figure 7h). In other terms, the data distribution can also be explained by a more restrictive model where depth is constant, $\bar{\sigma}_{x}^{p}=\Phi, \theta=90^{\circ}$ (or $\bar{\sigma}_{x}^{r}=1 / \Phi$, cf. Figure 6) and $\alpha_{p}$ and $\alpha_{r}$ are free parameters. This model has previously been employed by Yamato and Brun (2017). Here, we extend their analysis by providing the associated pressure-to-depth conversion.

To obtain a mathematical expression for $P_{p}$, we substitute Equation 14 with $\bar{\sigma}_{x}=\Phi$ for $\bar{P}$ in Equation 16 and solve for $P$. For $P_{r}$, we use Equation 13 with $\bar{\sigma}_{x}=1 / \Phi$ instead of Equation 14 . This process yields:

$$
\begin{aligned}
& P_{p}=\frac{\rho g z}{3}\left(2-\alpha^{p}+\Phi\left(1+\alpha^{p}\right)\right) \\
& P_{r}=\frac{\rho g z}{3}\left(1+\alpha^{r}+\Phi^{-1}\left(2-\alpha^{r}\right)\right)
\end{aligned}
$$

Similar to previous figures, Figure 8 shows the domain of the solution of Equations 21 and 22 for values of $\alpha_{p}$ and $\alpha_{r}$ between 0 and 1. Data points are also plotted in this $P_{p}$ versus $P_{r}$ space. We also show contours of 
depth obtained by solving Equations 21 or 22 for $z$. The value of $\rho g$ influences the distance between depth contours but not the shape of the solution domain. The parameter $\Phi$ (or $\phi$, cf. Equation 11) controls the orientation and opening angle of the fan-shaped solution domain. The outlier points (gray) lie outside the solution domain, while the other data points (colored) lie within it or close to its boundary. The location of a point within the solution domain reflects the depth and mode of deformation under peak and retrograde conditions $\left(\alpha_{p}, \alpha_{r}\right)$. Points along the central line $\alpha_{p}=\alpha_{r}$ have the same mode of deformation in the peak and retrograde stages. Points below this line deform by flattening under peak conditions and by constriction under retrograde conditions, and points lying above the central line deform by constriction under peak conditions and by flattening under retrograde conditions. Samples from one orogen tend to span a large range of $\alpha_{p}, \alpha_{r}$ that could reflect local differences in the mode of deformation.

For a given depth, a range of $P_{p}, P_{r}$ is possible depending on the value of $\alpha_{r}, \alpha_{p}$ (see Equations 21 and 22). The opposite is also true: for a given $P_{p}, P_{r}$, there is a range of possible depths. We represent the lower and upper estimates of this range in Figures $8 \mathrm{a}$ and $8 \mathrm{~b}$, respectively. In this model, all points lie below the "deepest Moho" reference depth for the lower depth estimate, and only one point is deeper than the "deepest Moho" when using the upper depth estimate.

\subsection{Depth Estimates Using the Two-Point Method}

Figure 9 shows depth estimates for our data according to the horizontal stress change-driven model and the stress rotation model ("S-model," thin bars) and the compression to extension model of the previous section ("YB-model," thick bars). Depth estimates for peak pressure assuming a lithostatic stress state (see Section 2.3) are also shown as the "L model" for reference (short bars).

In the following passage, we use the terms L-, $\mathrm{S}$-, and YB-depth to refer to the depth estimates according to the L-, S-, and YB-models, respectively. The methods for computing the depth ranges for the S- and YB-model are given in $\mathrm{A}$.

The minimum and maximum YB-depths are equal for points on the border of the solution domain fan, while the range is largest for points along the central line (Figure 8). The range of S-depth tends to be larger for points with a low $P_{p} / P_{r}$ ratio and decreases with increasing $P_{p} / P_{r}$ (because fewer solutions exist; see Figures 6 and 7). For all samples except the outliers, the S- and YB-depths are significantly lower than the L-depth. For example, one point in Kokchetav and one point in Sulu-Dabie have L-depths $>160 \mathrm{~km}$, whereas their S- and YB-depths are $65-70 \mathrm{~km}$ and $60-85 \mathrm{~km}$, respectively. For outliers, the upper estimate of the $\mathrm{S}$-depth is close to the L-depth. In the L-model, the depth is proportional to the peak pressure. Thus, large differences in peak pressure between two samples result in large differences in depth. However, the S- and YB-models take both peak and retrograde pressures into account, which can smooth out this difference. For example, the two data points with the highest pressures in the Alps have L-depths of 95 and $125 \mathrm{~km}$, whereas the maximum S-depth is $70 \mathrm{~km}$ for both. Conversely, points with the same L-depth (i.e., same peak pressure) can have different YB- and S-depths. This contrast is best exemplified by comparing points with the same $P_{p}$ in Figure 8: points in the upper half of the fan $\left(\alpha_{p}>\alpha_{r}\right)$ align on a lower depth estimate contour, while points in the lower half of the fan $\left(\alpha_{p}<\alpha_{r}\right)$ align on the upper depth estimate contour. Thus, at constant $P_{p}$, the mean depth estimate increases with increasing $P_{r}$, and the uncertainty increases toward the center of the fan $\left(\alpha_{p}=\alpha_{r}\right.$ line). For example, for points at $P_{p}=3 \mathrm{GPa}$, the mean depth estimate increases from $40 \mathrm{~km}$ at $P_{r}=0.6 \mathrm{GPa}$ to $60 \mathrm{~km}$ at $P_{r}=1.2 \mathrm{GPa}$. At these two extreme $P_{r}$ values, the depth estimate has a unique value, while at the center of the fan $\left(P_{r}=0.85 \mathrm{GPa}\right)$, the depth estimate ranges between 40 and $60 \mathrm{~km}$. Overall, the most striking features of the S- and YB-models are that all data points have at least part of their range shallower than the "deepest Moho" line and that the deepest S-depth is $\sim 90 \mathrm{~km}$ compared to $165 \mathrm{~km}$ for the L-depth.

\section{Discussion}

Pressure is a function of both depth, deviatoric stresses and volumetric stress. However, since deviatoric and volumetric stress cannot be measured, pressure-to-depth conversions require assumptions. In the previous sections, we propose several pressure-to-depth conversion methods involving one or two pressure data points. For simplicity, we ignored volumetric stress. In particular, we show that the proportionality between 


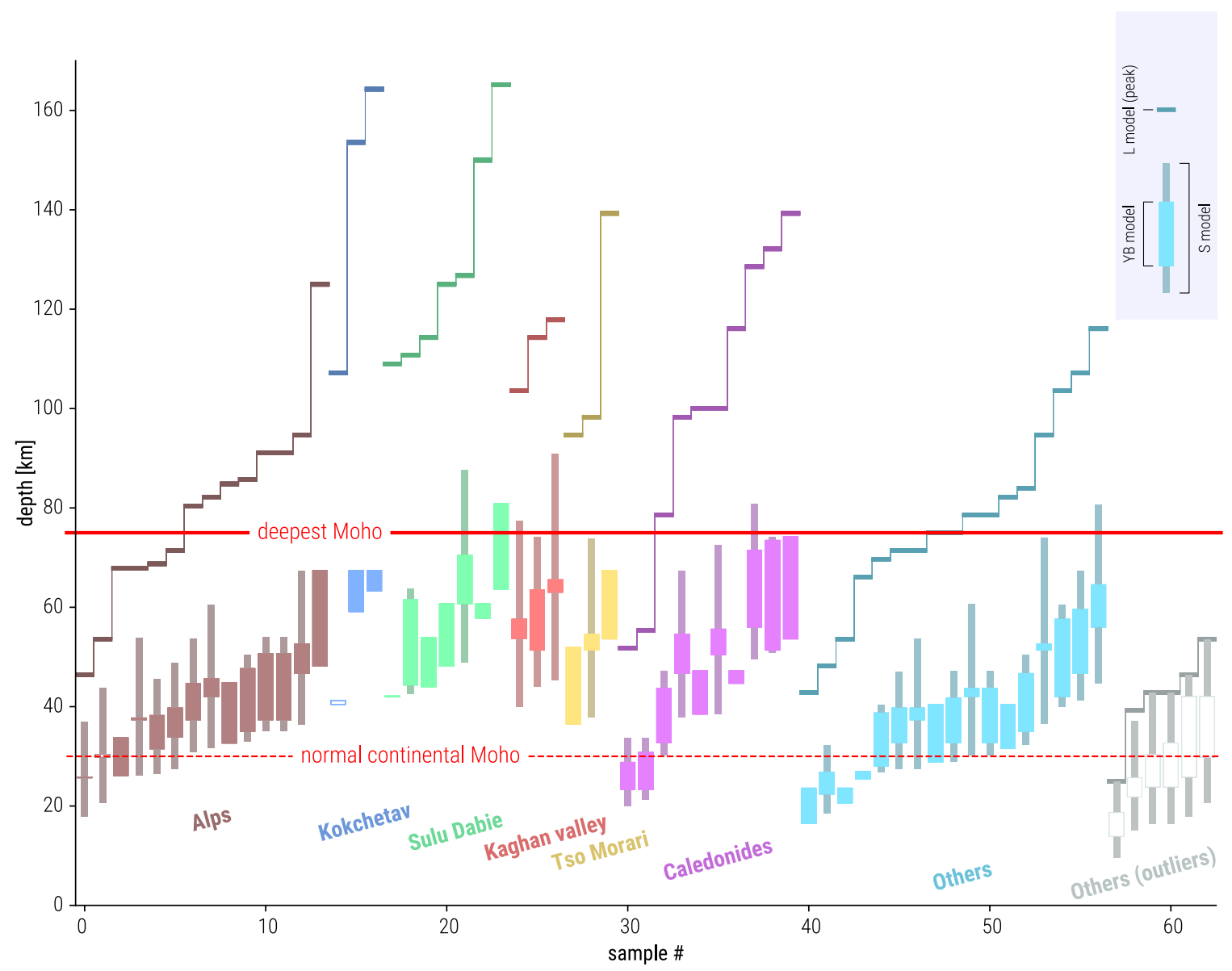

Figure 9. Estimated depth of each sample using the two-point method of pressure-to-depth conversion. The graph also shows depth estimates using the one-point lithostatic case for reference. L-model: peak pressure in the one-point lithostatic case. S-model refers to the models described in Sections 3.1 and 3.2 The YB-model refers to the model described in Section 3.3. For the YB-model, filled rectangles indicate depth estimates for points that lie within the model boundaries, while open rectangles apply to points outside the model boundaries. The depth estimates indicated by open rectangles are relevant for points close to the model boundary (e.g., samples \#1 and \#14) but less relevant for points far from the boundary (i.e., category Others [outliers]). This figure can be reproduced using the computer script from supporting information S9.

$P_{p}$ and $P_{r}$ can be explained by a model where $P_{p}$ and $P_{r}$ are recorded by the rock at the same depth but under different stress states (Figures 6-8). For simplicity, we only present two-point models with either stress rotation or horizontal stress magnitude change and no exhumation. Combining rotation and magnitude change may further decrease the magnitude of deviatoric stresses required to explain the data. Relaxing the assumption that $z_{p}=z_{r}$ and accounting for some exhumation would also decrease the magnitude of deviatoric stresses required.

\subsection{Perspectives on Using Strain Data}

In our formulation of the pressure-to-depth conversion, we use $\alpha$ instead of a stress value (see Equation 4). $\alpha$ characterizes the shape of the stress ellipsoid and is thus similar to commonly used parameters for characterizing the shape of ellipsoid such as Lode's ratio or Flinn's $k$-value (Mookerjee \& Peek, 2014). Because strain results from applied stress, obtaining a value for $\alpha$ using markers of deformation could provide key data to better constrain depth. The two-point models relying on a change in the magnitude of horizontal stress (Figure 6) or stress orientation (Figure 7) give ambiguous results since both models can explain the data. However, the predictions of the model could be falsified based on stress rotation (Figure 7) by using the directions of the strain ellipsoid or paleostress inversion of fault orientations to estimate stress directions. 


\subsection{Data Distribution and Model}

The data suggest that $P_{p}$ and $P_{r}$ are proportional (see Figure 1). However, by using the one-point method, because $P_{p}$ and $P_{r}$ are considered independently, it is difficult to explain this proportionality. In the lithostatic case, for instance, the decompression from $P_{p}$ to $P_{r}$ is controlled only by the exhumation of rocks. However, the currently proposed exhumation mechanisms (e.g., subduction channels and corner flows) do not suggest that exhumation would be proportional to maximum depth. On the other hand, the two-point model treats both $P_{p}$ and $P_{r}$ together. Since we assume that $z_{p}=z_{r}$, the maximum change from $P_{p}$ to $P_{r}$ is limited by Byerlee's law, and the yield stress function is linearly dependent on $P$. Considering reasonable values for the friction coefficient (e.g., 0.65), the limits of the model outline the distribution of the data. For example, for the models shown in Figures $6 \mathrm{j}$ and $7 \mathrm{~h}$, the extent of the model domain outlines the upper extent of the distribution, and the lower limit of the model corresponds to the lower extent for outliers.

The YB-model simulates the case where rocks are brittle in both compression and extension and thus constitutes a particular case of the two-point model. It is interesting to note that although the YB-model allows us to largely explain the data, it excludes the outliers (Figure 8). However, all data (including outliers) can be explained considering the more general S-models (Figures 6 and 7).

The upper extent of the data distribution $\left(P_{p} / P_{r} 4.8\right)$ can only be explained when $\bar{\sigma}_{x}^{p}=\Phi, \alpha_{p}=1$ (brittle constrictive deformation in compression) and $\bar{\sigma}_{x}^{r}=1 / \Phi, \alpha_{r}=0$ (brittle flattening deformation in extension). The lower extent of the data distribution excluding outliers $\left(P_{p} / P_{r} 2.4\right)$, however, can have several explanations. In the YB-model, it corresponds to $\alpha_{p}=0, \alpha_{r}=1$. For S-models (e.g., Figures 6g, 6i, 6j, 7e, 7g, and $7 \mathrm{~h}$ ), the lower bound of the data can be within the solution domain and coincides with different values of $\bar{\sigma}_{x}^{r}$ or $\theta$. Interestingly, the lower limit coincides with $\mathrm{Sxr}=1$ (i.e., lithostatic case) in Figure 6j. Two-point models can fit all data points from the data set (or lie very close to the model boundary), which suggests that in all orogens, a change in stress state may be responsible for the decompression from $P_{p}$ to $P_{r}$. The different predictions in terms of the change mode of deformation $\left(\alpha_{p}\right.$ to $\left.\alpha_{r}\right)$ bring additional constraints concerning the mechanism responsible for the change in the stress state. Monitoring the evolution of $\alpha$ in 3D numerical geodynamic models may provide more answers.

Furthermore, the pressure data are not direct measurements but the result of models based on for example, Gibbs energy minimization. Those models themselves contain approximations and assumptions such as the existence of a local thermodynamic equilibrium or homogeneous pressure.

\subsection{Other Causes of Over/Under-Pressure}

The models presented here explain pressure variations in a homogeneous material subjected to a change in depth or deviatoric stresses. In a heterogeneous system, the pressure in one material may be affected by deviatoric stresses in another material. A well-studied example is the case of an elliptical inclusion embedded in an elastic or linear viscous matrix. In this system, the magnitude and sense of deviatoric stresses are functions of the relative strength between the matrix and the inclusion, as well as the orientation of the inclusion in the stress field (Moulas et al., 2014; Schmid \& Podladchikov, 2003, 2005). The pressure in the inclusion is controlled both by the stress state in the inclusion and by the stress state in the host rock. An important point is that deviatoric stresses in a weak inclusion may be negligible, while the pressure can still be as high as $\sigma_{1}=\Phi$ in a strong host rock. This is very different from a homogeneous material where the pressure is lithostatic in the absence of deviatoric stresses. Thus, pressure can vary between the values of $\sigma_{3}$ and $\sigma_{1}$ for the strongest material in the inclusion/host system, whereas in a homogeneous material, pressure can vary only between $2 / 3 \sigma_{3}+1 / 3 \sigma_{1}$ and $1 / 3 \sigma_{3}+2 / 3 \sigma_{1}$ (see Equation 6 ) (Moulas et al., 2014, 2019; Schmalholz \& Podladchikov, 2013). Field examples of this phenomenon have been documented by Luisier et al. (2019) in the Monte Rosa nappe (Alps) and by Jamtveit et al. (2018) in the Bergen Arc (Caledonides). In addition, Jamtveit et al. (2018) already noted that $\sigma_{2}$ can play an important role in the generation of overpressure. Pressure deviations can also be caused by, among other, lateral variations of gravity potential energy (Schmalholz et al., 2014, 2019), volume changes (Vrijmoed et al., 2010), elastic bending (Reuber et al., 2016), or grain-scale diffusion of elements (Tajčmanová et al., 2015; Zhong et al., 2017). 


\subsection{Local Versus Regional Stress State}

In this study, we present several methods that can be used to determine possible stress states associated with peak and metamorphic pressures. Stress states are by essence local. Some researchers even propose that metamorphic pressure may reflect the stress state in only a single grain (see the discussion about inclusions in the previous paragraph) and that large pressure gradients responsible for pressure differences on the order of GPa can be recorded within a single grain (Tajčmanová et al., 2014, 2015). In our data set, samples from the same region have a wide variety of $P_{p} / P_{r}$ ratios (see Figure 1c) and are often distributed from one side of the fan to another (between $P_{p} / P_{r}=1.4$ and $P_{p} / P_{r}=4.8$ ), which indicates differences in the change in stress magnitude, stress orientation or relative magnitude of $\sigma_{2}(\alpha)$. This could be an indication that pressure data reflect the local (grain-to $10 \mathrm{~km}$-scale) rather than regional $(100 \mathrm{~km})$ stress state. Thus, using the stress states determined in this study to interpret regional-scale processes requires taking some caution. For example, the YB-model assumes that the peak to retrograde pressure can be explained by a transition from a compressional to an extensional stress state, with both stress states close to the brittle limit. These stress states reflect $\mathrm{km}$-scale conditions or are smaller in the sense that the whole system is submitted to convergence (i.e., in Figure 1). The distance between two points far from the subduction zone, one located on the subducting plate and the other located on the overriding plate, is constantly decreasing, but the part undergoing exhumation is locally subjected to extension. This corresponds well with the fact that the exhumation of a coherent metamorphic unit is impossible without a normal fault on top. As we have shown, stress orientation has a strong control on pressure changes, and in a complex orogen, stress orientations can vary significantly in space and time, for example, due to changes in the subduction angle or the friction along the plate boundary (Wang \& Hu, 2006), the proximity to magma chambers (Gerbault et al., 2018) or faults (e.g., Martínez-Díaz, 2002; Maerten et al., 2002; Shao \& Hou, 2019), or the position within the orogen (e.g., Kastrup et al., 2004).

\subsection{Implications for Geodynamic Models}

Rock strength strongly depends on temperature. Hence, considering classic rheological yield stress envelopes (e.g., Burov, 2011), it seems inadequate to consider large deviatoric stresses deep in the lithosphere $(>120 \mathrm{~km})$ due to the temperature increase with depth. This statement could favor using lithostatic pressure-to-depth conversion but remains debatable. Indeed, the depth estimates using the S- and YB-models are consistent with the depth of the crustal roots of orogens, and in these places (i.e., at the base of the crust or in the lithospheric mantle), significant deviatoric stresses are possible. Significant deviatoric stresses are even more likely at this depth in a subduction zone with a cold geotherm.

Several elements suggest significant deviatoric stresses near the Moho depth: (1) earthquakes are not uncommon at such depths in a subduction context and provide evidence that brittle deformation can occur (e.g., Hacker et al., 2003; Hetényi et al., 2007), and (2) several field and petrological studies have already evidenced brittle deformation associated with HP metamorphism (e.g., Angiboust et al., 2012; Austrheim \& Boundy, 1994; Hertgen et al., 2017; John \& Schenk, 2006; Yang et al., 2014).

Samples with high $P_{p} / P_{r}$ require a stress field close to the brittle limit using the S-model (e.g., Figure 7). However, samples with $P_{p} / P_{r}<\Phi$ are consistent with a stress state where the magnitude of the deviatoric stress (second invariant) is only half that required for brittle deformation (i.e., $\bar{\sigma}_{x}^{p}=(1+\Phi) / 2$ ) when peak pressure is recorded. This means that even in the ductile realm, the effect of the deviatoric stresses should not be neglected.

The release of fluids from dewatering metamorphic reactions can decrease the effective pressure. Thus, an increase of fluid pressure could trigger the transition from $P_{p}$ to $P_{r}$. However, this mechanism seems unlikely because fluid pressure would need to remain high during exhumation (otherwise, a new peak pressure would be recorded). Townend and Zoback (2000) argue that high fluid pressure leads to rock fracturing, which creates space and thus causes fluid pressure to decrease. 


\section{Conclusion}

In this contribution, we reviewed the basic mathematical formulations of pressure-to-depth conversion for a homogeneous rock. First, we derived the standard "one-point method of pressure-to-depth conversion" and applied it to a large data set of metamorphic pressures to independently estimate a range of depths at which rocks may have recoded their peak $\left(P_{p}\right)$ and retrograde pressures $\left(P_{r}\right)$. Since the most common assumption in the literature is to consider that metamorphic pressure corresponds to the lithostatic pressure, we used this "lithostatic case" as a reference.

By introducing deviatoric stress components and considering only the compressional stress regime $\left(\sigma_{1}\right.$ horizontal) at $P_{p}$ and both compressional and extensional ( $\sigma_{1}$ vertical) stress regimes for $P_{r}$, we showed that the deviations from the reference case can be significant. For $P_{p}$, the estimated depths vary between $40 \%$ and $100 \%$ of the reference case. For $P_{r}$, the estimated depth range is $40 \%-185 \%$ of the reference case. Thus, under our assumption, the lithostatic case represents an upper bound estimate of depth for $P_{p}$ and an intermediate value for $P_{r}$. Moreover, the uncertainty ranges of both peak $\left(z_{p}\right)$ and retrograde $\left(z_{r}\right)$ depths are large enough to lead to overlap for these two depth estimates. This means that the transition from $P_{p}$ to $P_{r}$ can be triggered by exhumation, a change in the stress state at constant depth, or a combination of both processes.

Second, we presented "two-point methods of pressure-to-depth conversion" that use both $P_{p}$ and $P_{r}$ to estimate depth under the hypothesis that $z_{p}=z_{r}$. For the two-point method, we considered two mechanisms of stress change between $P_{p}$ and $P_{r}$ : (1) change in the magnitude of horizontal stresses and (2) rotation of the stress state. We also treated a particular case where the magnitude of deviatoric stresses is maximum, and the stress regime varies from compression at $P_{p}$ to extension at $P_{r}$. The two-point method greatly decreases the uncertainty range of depth estimates and yields stricter constraints on the possible stress state. Remarkably, all $P_{p}, P_{r}$ points in our data set are consistent with a change in the stress state at a constant depth.

In our data set, the maximum depth estimates under the "lithostatic assumption" are $\sim 160 \mathrm{~km}$ for $P_{p}$ and $50 \mathrm{~km}$ for $P_{r}$. Thus, the lithostatic assumption requires deep burial and exhumation from great depth. On the other hand, the two-point models reveal that points in our data set are consistent with depths shallower than $75 \mathrm{~km}$ (i.e., the current deepest Moho). This suggests instead that all metamorphic rocks in our data set have been buried at crustal depths with no (or only minor) exhumation between $P_{p}$ and $P_{r}$. The validity of either of these models cannot be assessed based only on pressure and temperature data. However, the principal stress directions and the relative magnitude of $\sigma_{2}$ (i.e., $\alpha$ ) may be estimated from the strain ellipsoid or paleostress analysis. Thus, a precise analysis of the deformation in association with the $P$ estimates in metamorphic rocks could validate or falsify depth estimates from the two-point model and further decrease the depth estimate uncertainty.

\section{Appendix A: Depth Estimates for the Two-Point Model}

\section{S-Model}

The depth estimate range for S-models is calculated numerically by testing a large array of combinations of $\bar{\sigma}_{x}^{p}, \alpha_{p}$ and $\alpha_{r}$ for each sample. The ranges considered are $1 \leq \bar{\sigma}_{x}^{p} \leq \Phi$ and $0 \leq \alpha_{p}, \alpha_{r} \leq 1$, and we use 50 values to discretize the range of each parameter for a total of $50^{3}=125,000$ parameter combinations. We proceed in two steps. First, we compute $\sigma_{z}$ using Equation 15 with $P=P_{p}, \bar{\sigma}_{x}=\bar{\sigma}_{x}^{p}$, and $\alpha=\alpha_{p}$, and we compute $z=\sigma_{z} /$ pg. Second, we need to test whether the previous solution is within the acceptable bounds of the model (i.e., not in the gray area of Figures 6-8). For this purpose, we compute $\bar{\sigma}_{x}^{r}$ using the following equation:

$$
\left\{\begin{array}{l}
\bar{\sigma}_{x}=\frac{3 P / \sigma_{z}-2+\alpha}{1+\alpha}, \text { when } \bar{\sigma}_{x} \leq 0, \\
\bar{\sigma}_{x}=\frac{3 P / \sigma_{z}-1-\alpha}{2-\alpha}, \text { when } \bar{\sigma}_{x} \geq 0,
\end{array}\right.
$$

with $P=P_{r}, \bar{\sigma}_{x}=\bar{\sigma}_{x}^{r}$, and $\alpha=\alpha_{r}$. Then, we test whether $1 / \Phi \leq \bar{\sigma}_{x}^{r} \leq \Phi$ and update the range of depth if the test is successful. 


\section{YB-Model}

To compute the range of depth for the YB-model, we use the minimum and upper estimates of depth whose contours are plotted in Figures $8 \mathrm{a}$ and $8 \mathrm{~b}$, respectively. In practice, we compute $\sigma_{z}$ using Equation 15 with parameters $\left[P, \alpha, \bar{\sigma}_{x}\right]$. For data points where $P_{p} / P_{r}>\Phi$ (i.e., above the line marked $\alpha_{p}=\alpha_{r}$ in Figure 8), we use parameters $\left[P_{p}, 1, \Phi\right]$ to compute $\min \left(\sigma_{z}\right)$, and $\left[P_{r}, 0,1 / \Phi\right]$ for $\max \left(\sigma_{z}\right)$. For data points where $P_{p} / P_{r} \leq \Phi$, we use $\left[P_{r}, 1,1 / \Phi\right]$ for $\min \left(\sigma_{z}\right)$ and $\left[P_{p}, 0, \Phi\right]$ for $\max \left(\sigma_{z}\right)$. Then, we compute $z=\sigma_{z} / \rho g$. In this algorithm, depth is calculated using either $\left[P_{p}, \alpha_{p}, \bar{\sigma}_{x}^{p}\right]$ or $\left[P_{r}, \alpha_{r}, \bar{\sigma}_{x}^{r}\right]$. If $\alpha_{p}$ is used as input, $\alpha_{r}$ can be computed back from $\sigma_{z}$, and we can perform the test $0 \leq \alpha_{r} \leq 1$ to verify that the solution is within the bounds of the model. If $\alpha_{r}$ is used as input, $\alpha_{p}$ is computed instead. If the test is successful, we plot the range as a colored box in Figure 9 or as an open box otherwise.

\section{Data Availability Statement}

The database used in this study including $\mathrm{Pp}, \mathrm{Tp}, \mathrm{Pr}$, and Tr estimates and the associated references is available from https://doi.org/10.5281/zenodo.4126862. Computer code (Jupyter notebooks) to reproduce most figures are available from https://doi.org/10.5281/zenodo.4276958 and as supporting information to this article.

\section{References}

\section{Acknowledgments
This work was supported by the} Japanese Society for the Promotion of Science (JSPS), Grant-in-Aid for Scientific Research no. JP18K13643. Thanks the IUF and Boost'Europe project (PréDiReM - project n17003298) that funded a part of this work. We thank Lucie Tajcmanova and an anonymous reviewer for their helpful comments. Philippe Yamato also especially thanks Guilhem Estournes who contributed to enrich the database initially collected. A special thought is also addressed to J. P. Brun who left us too early. He is acknowledged for his constant scientific support and endless discussions on the meaning of pressure.
Agard, P., Yamato, P., Jolivet, L., \& Burov, E. (2009). Exhumation of oceanic blueschists and eclogites in subduction zones: Timing and mechanisms. Elsevier. https://doi.org/10.1016/j.earscirev.2008.11.002

Anderson, E. M. (1905). The dynamics of faulting. Transactions of the Edinburgh Geological Society, 8(3), 387-402. https://doi.org/10.1144/ transed.8.3.387

Angiboust, S., Agard, P., Yamato, P., \& Raimbourg, H. (2012). Eclogite breccias in a subducted ophiolite: A record of intermediate depth earthquakes?. Geology, 40(8), 707-710. https://doi.org/10.1130/G32925.1

Austrheim, H., \& Boundy, T. M. (1994). Pseudotachylytes generated during seismic faulting and eclogitization of the deep crust. Science, 265(5168), 82-83. https://doi.org/10.1126/science.265.5168.82

Beaumont, C., Jamieson, R. A., Butler, J. P., \& Warren, C. J. (2009). Crustal structure: A key constraint on the mechanism of ultra-high-pressure rock exhumation. Earth and Planetary Science Letters, 287(1-2), 116-129. https://doi.org/10.1016/j.epsl.2009.08.001

Beltrando, M., Hermann, J., Lister, G., \& Compagnoni, R. (2007). On the evolution of orogens: Pressure cycles and deformation mode switches. Earth and Planetary Science Letters, 256(3-4), 372-388. https://doi.org/10.1016/j.epsl.2007.01.022

Brace, W. F., Ernst, W. G., \& Kallberg, R. W. (1970). An experimental study of tectonic overpressure in Franciscan rocks. GSA Bulletin, 81(5), 1325-1338. https://doi.org/10.1130/0016-7606(1970)81[1325:aesoto]2.0.co;2

Brun, J. P., \& Faccenna, C. (2008). Exhumation of high-pressure rocks driven by slab rollback. Earth and Planetary Science Letters, 272(12), 1-7. https://doi.org/10.1016/j.epsl.2008.02.038

Burov, E. B. (2011). Rheology and strength of the lithosphere. Marine and Petroleum Geology, 28(8), 1402-1443. https://doi.org/10.1016/j. marpetgeo.2011.05.008

Burov, E., Francois, T., Yamato, P., \& Wolf, S. (2014). Mechanisms of continental subduction and exhumation of HP and UHP rocks. Gondwana Research, 25(2), 464-493. https://doi.org/10.1016/j.gr.2012.09.010

Butler, J. P., Beaumont, C., \& Jamieson, R. A. (2013). The Alps 1: A working geodynamic model for burial and exhumation of (ultra) high-pressure rocks in Alpine-type orogens. Earth and Planetary Science Letters, 377-378, 114-131. https://doi.org/10.1016/j. epsl.2013.06.039

Butler, J. P., Beaumont, C., \& Jamieson, R. A. (2014). The Alps 2: Controls on crustal subduction and (ultra)high-pressure rock exhumation in Alpine-type orogens. Journal of Geophysical Research: Solid Earth, 119(7), 5987-6022. https://doi.org/10.1002/2013JB010799

Byerlee, J. (1978). Friction of rocks. Pure and Applied Geophysics PAGEOPH, 116(4-5), 615-626. https://doi.org/10.1007/BF00876528

Chopin, C. (2003). Ultrahigh-pressure metamorphism: Tracing continental crust into the mantle. Earth and Planetary Science Letters, 212(1-2), 1-14. https://doi.org/10.1016/S0012-821X(03)00261-9

Ernst, W. G. (1963). Significance of Phengitic Micas From Low-Grade Schists-American Mineralogist-GeoScienceWorld. American Mineralogist, 48(11-12), 1357-1373.

Ernst, W. G., Hacker, B. R., \& Liou, J. G. (2007). Petrotectonics of ultrahigh-pressure crustal and upper-mantle rocks-Implications for Phanerozoic collisional orogens. The Geological Society of America, 433, $27-49$.

Froitzheim, N., Pleuger, J., Roller, S., \& Nagel, T. (2003). Exhumation of high- and ultrahigh-pressure metamorphic rocks by slab extraction. Geology, 31(10), 925-928. https://doi.org/10.1130/G19748.1

Gerbault, M., Hassani, R., Novoa Lizama, C., \& Souche, A. (2018). Three-dimensional failure patterns around an inflating magmatic chamber. Geochemistry, Geophysics, Geosystems, 19(3), 749-771. https://doi.org/10.1002/2017GC007174

Gerya, T. (2015). Tectonic overpressure and underpressure in lithospheric tectonics and metamorphism. Journal of Metamorphic Geology, 33(8), 785-800. https://doi.org/10.1111/jmg.12144

Godard, G. (2001). Eclogites and their geodynamics interpretation: A history. Journal of Geodynamics, 32(1-2), 165-203. https://doi. org/10.1016/S0264-3707(01)00020-5

Green, H. W. (2005). Psychology of a changing paradigm: 40+ Years of high-pressure metamorphism. International Geology Review, 47(5), 439-456. https://doi.org/10.2747/0020-6814.47.5.439

Guillot, S., Hattori, K., Agard, P., Schwartz, S., \& Vidal, O. (2009). Exhumation processes in oceanic and continental subduction contexts: A review. S. Lallemand \& F. Funiciello In Subduction zone geodynamics (pp. 175-205). Berlin, Heidelberg: Springer. https://doi. org/10.1007/978-3-540-87974-9-10 
Hacker, B. R., \& Gerya, T. V. (2013). Paradigms, new and old, For ultrahigh-pressure tectonism (Vol. 603). https://doi.org/10.1016/j. tecto.2013.05.026

Hacker, B., Peacock, S., Abers, G., \& Holloway, S. (2003). Subduction factory 2. Are intermediate-depth earthquakes in subducting slabs linked to metamorphic dehydration reactions?. Journal of Geophysical Research, 108, 2030. https://doi.org/10.1029/2001JB001129

Hertgen, S., Yamato, P., Morales, L. F., \& Angiboust, S. (2017). Evidence for brittle deformation events at eclogite-facies P-T conditions (example of the Mt. Emilius klippe, Western Alps). Tectonophysics, 706-707, 1-13. https://doi.org/10.1016/j.tecto.2017.03.028

Hetényi, G., Cattin, R., Brunet, F., Bollinger, L., Vergne, J., Nábělek, J. L., et al. (2007). Density distribution of the India plate beneath the Tibetan plateau: Geophysical and petrological constraints on the kinetics of lower-crustal eclogitization. Earth and Planetary Science Letters, 264(1-2), 226-244. https://doi.org/10.1016/j.epsl.2007.09.036

Hobbs, B. E., \& Ord, A. (2017). Pressure and equilibrium in deforming rocks. Journal of Metamorphic Geology, 35(9), 967-982. https://doi. org/10.1111/jmg.12263

Hobbs, B., \& Ord, A. (2015). Dramatic effects of stress on metamorphic reactions: Comment (Vol. 43) (No. 11). Geological Society of America. https://doi.org/10.1130/G37070C.1

Huw Davies, J., \& von Blanckenburg, F. (1995). Slab breakoff: A model of lithosphere detachment and its test in the magmatism and deformation of collisional orogens. Earth and Planetary Science Letters, 129(1-4), 85-102. https://doi.org/10.1016/0012-821X(94)00237-S

Jamieson, J. C. (1963). Possible occurrence of exceedingly high pressures in geological processes. GSA Bulletin, 74(8), 1067-1070. https:// doi.org/10.1130/0016-7606(1963)74[1067:pooehp]2.0.co;2

Jamtveit, B., Moulas, E., Andersen, T. B., Austrheim, H., Corfu, F., Petley-Ragan, A., et al. (2018). High pressure metamorphism caused by fluid induced weakening of deep continental crust. Scientific Reports, 8(1), 1-8. https://doi.org/10.1038/s41598-018-35200-1

John, T., \& Schenk, V. (2006). Interrelations between intermediate-depth earthquakes and fluid flow within subducting oceanic plates: Constraints from eclogite facies pseudotachylytes. Geology, 34(7), 557-560. https://doi.org/10.1130/G22411.1

Kastrup, U., Zoback, M. L., Deichmann, N., Evans, K. F., Giardini, D., \& Michael, A. J. (2004). Stress field variations in the Swiss Alps and the northern Alpine foreland derived from inversion of fault plane solutions. Journal of Geophysical Research, 109(B1), B01402. https:// doi.org/10.1029/2003jb002550

Luisier, C., Baumgartner, L., Schmalholz, S. M., Siron, G., \& Vennemann, T. (2019). Metamorphic pressure variation in a coherent Alpine nappe challenges lithostatic pressure paradigm. Nature Communications, 10(1), 1-11. https://doi.org/10.1038/s41467-019-12727-z

Maerten, L., Gillespie, P., \& Pollard, D. D. (2002). Effects of local stress perturbation on secondary fault development. Journal of Structural Geology, 24(1), 145-153. https://doi.org/10.1016/S0191-8141(01)00054-2

Mancktelow, N. S. (2008). Tectonic pressure: Theoretical concepts and modelled examples. Lithos, 103(1-2), 149-177. https://doi. org/10.1016/J.LITHOS.2007.09.013

Mancktelow, N. S. (1993). Tectonic overpressure in competent mafic layers and the development of isolated eclogites. Journal of Metamorphic Geology, 11(6), 801-812. https://doi.org/10.1111/j.1525-1314.1993.tb00190.x

Martínez-Díaz, J. J. (2002). Stress field variation related to fault interaction in a reverse oblique-slip fault: The Alhama de Murcia fault, Betic Cordillera, Spain. Tectonophysics, 356(4), 291-305. https://doi.org/10.1016/S0040-1951(02)00400-6

Mookerjee, M., \& Peek, S. (2014). Evaluating the effectiveness of Flinn's k-value versus Lode's ratio. Journal of Structural Geology, 68(PA), 33-43. https://doi.org/10.1016/j.jsg.2014.08.008

Moulas, E., Burg, J. P., \& Podladchikov, Y. (2014). Stress field associated with elliptical inclusions in a deforming matrix: Mathematical model and implications for tectonic overpressure in the lithosphere. Tectonophysics, 631(C), 37-49. https://doi.org/10.1016/j. tecto.2014.05.004

Moulas, E., Podladchikov, Y. Y., Aranovich, L. Y., \& Kostopoulos, D. (2013). The problem of depth in geology: When pressure does not translate into depth. Petrology, 21(6), 527-538. https://doi.org/10.1134/S0869591113060052

Moulas, E., Schmalholz, S. M., Podladchikov, Y., Tajčmanová, L., Kostopoulos, D., \& Baumgartner, L. (2019). Relation between mean stress, thermodynamic, and lithostatic pressure. Journal of Metamorphic Geology, 37(1), 1-14. https://doi.org/10.1111/jmg.12446

Nagel, T. J. (2008). Tertiary subduction, collision and exhumation recorded in the Adula nappe, central Alps. Geological Society - Special Publications, 298(1), 365-392. https://doi.org/10.1144/SP298.17

Parrish, R. R., Gough, S. J., Searle, M. P., \& Waters, D. J. (2006). Plate velocity exhumation of ultrahigh-pressure eclogites in the Pakistan Himalaya. Geology, 34(11), 989-992. https://doi.org/10.1130/G22796A.1

Petrini, \& Podladchikov. (2000). Lithospheric pressure-depth relationship in compressive regions of thickened crust. Journal of Metamorphic Geology, 18(1), 67-77. https://doi.org/10.1046/j.1525-1314.2000.00240.x

Platt, J. P. (1986). Dynamics of orogenic wedges and the uplift of high-pressure metamorphic rocks. GSA Bulletin, 97(9), 1037-1053. https://doi.org/10.1130/0016-7606(1986)97〈1037:doowat〉2.0.co;2

Pleuger, J., \& Podladchikov, Y. Y. (2014). A purely structural restoration of the NFP20-East cross section and potential tectonic overpressure in the Adula nappe (central Alps). Tectonics, 33(5), 656-685. https://doi.org/10.1002/2013TC003409

Reuber, G., Kaus, B. J., Schmalholz, S. M., \& White, R. W. (2016). Nonlithostatic pressure during subduction and collision and the formation of (ultra)high-pressure rocks. Geology, 44(5), 343-346. https://doi.org/10.1130/G37595.1

Ring, U., Brandon, M. T., Willett, S. D., \& Lister, G. S. (1999). Exhumation processes. Geological Society Special Publication. https://doi. org/10.1144/GSL.SP.1999.154.01.01

Rubatto, D., \& Hermann, J. (2001). Exhumation as fast as subduction?. Geology, 29(1), 3-6. https://doi.org/10.1130/0091-7613(2001)029/ 0003:eafas $>2.0 . \mathrm{co} ; 2$

Rubatto, D., Regis, D., Hermann, J., Boston, K., Engi, M., Beltrando, M., et al. (2011). Yo-yo subduction recorded by accessory minerals in the Italian Western Alps. Nature Geoscience, 4(5), 338-342. https://doi.org/10.1038/ngeo1124

Schenker, F. L., Schmalholz, S. M., Moulas, E., Pleuger, J., Baumgartner, L. P., Podladchikov, et al. (2015). Current challenges for explaining (ultra)high-pressure tectonism in the Pennine domain of the Central and Western Alps. Journal of Metamorphic Geology, 33(8), 869-886. https://doi.org/10.1111/jmg.12143

Schmalholz, S. M., \& Podladchikov, Y. Y. (2013). Tectonic overpressure in weak crustal-scale shear zones and implications for the exhumation of high-pressure rocks. Geophysical Research Letters, 40(10), 1984-1988. https://doi.org/10.1002/grl.50417

Schmalholz, S. M., \& Schenker, F. L. (2016). Exhumation of the Dora Maira ultrahigh-pressure unit by buoyant uprise within a low-viscosity mantle oblique-slip shear zone. Terra Nova, 28(5), 348-355. https://doi.org/10.1111/ter.12227

Schmalholz, S. M., Duretz, T., Hetenyi, G., \& Medvedev, S. (2019). Distribution and magnitude of stress due to lateral variation of gravitational potential energy between Indian lowland and Tibetan plateau. Geophysical Journal International, 216(2), 1313-1333. https://doi. org/10.1093/gji/ggy463 
Schmalholz, S. M., Medvedev, S., Lechmann, S. M., \& Podladchikov, Y. (2014). Relationship between tectonic overpressure, deviatoric stress, driving force, isostasy and gravitational potential energy. Geophysical Journal International, 197(2), 680-696. https://doi. org/10.1093/gji/ggu040

Schmalholz, S. M., \& Podladchikov, Y. (2014). Metamorphism under stress: The problem of relating minerals to depth. Geological Society of America. https://doi.org/10.1130/focus0822014.1

Schmid, S. M., Pfiffner, O. A., Froitzheim, N., Schönborn, G., \& Kissling, E. (1996). Geophysical-geological transect and tectonic evolution of the Swiss-Italian Alps. Tectonics, 15(5), 1036-1064. https://doi.org/10.1029/96TC00433

Schmid, D. W., \& Podladchikov, Y. Y. (2003). Analytical solutions for deformable elliptical inclusions in general shear. Geophysical Journal International, 155(1), 269-288. https://doi.org/10.1046/j.1365-246X.2003.02042.X

Schmid, D. W., \& Podladchikov, Y. Y. (2005). Mantled porphyroclast gauges. Journal of Structural Geology, 27(3), 571-585. https://doi. org/10.1016/j.jsg.2004.09.005

Shao, B., \& Hou, G. (2019). The interactions of fault patterns and stress fields during active faulting in Central North China Block: Insights from numerical simulations. PLos One, 14(4), e0215893. https://doi.org/10.1371/journal.pone.0215893

Tajčmanová, L., Podladchikov, Y., Powell, R., Moulas, E., Vrijmoed, J., \& Connolly, J. (2014). Grain-scale pressure variations and chemical equilibrium in high-grade metamorphic rocks. Journal of Metamorphic Geology, 32(2), 195-207. https://doi.org/10.1111/jmg.12066

Tajčmanová, L. (2015)Deviations from lithostatic pressure during metamorphism: fact or fiction?. Journal of Metamorphic Geology, 33(8), 783-784. https://doi.org/10.1111/jmg.12152

Tajčmanová, L., Vrijmoed, J., \& Moulas, E. (2015). Grain-scale pressure variations in metamorphic rocks: implications for the interpretation of petrographic observations. Lithos, 216-217, 338-351. https://doi.org/10.1016/j.lithos.2015.01.006

Townend, J., \& Zoback, M. D. (2000). How faulting keeps the crust strong: Comment and reply. Geology, 28(5), 399-402. https://doi. org/10.1130/0091-7613(2000)28<399:HFKTCS $>2.0 . C O$

Vrijmoed, J. C., Podladchikov, Y. Y., Andersen, T. B., \& Hartz, E. H. (2010). An alternative model for ultra-high pressure in the Svartberget Fe-Ti garnet-peridotite, Western Gneiss Region, Norway. European Journal of Mineralogy, 21(6), 1119-1133. https://doi. org/10.1127/0935-1221/2009/0021-1985

Wang, K., \& Hu, Y. (2006). Accretionary prisms in subduction earthquake cycles: The theory of dynamic Coulomb wedge. Journal of Geophysical Research, 111(6), 1-16. https://doi.org/10.1029/2005JB004094

Warren, C. J. (2013). Exhumation of (ultra-)high-pressure terranes: concepts and mechanisms. Solid Earth, 4(1), 75-92. https://www. solid-earth.net/4/75/2013/10.5194/se-4-75-2013

Wheeler, J. (1991). Structural evolution of a subducted continental sliver: The northern Dora Maira Massif, Italian Alps. Journal of the Geological Society, 148(6), 1101-1113. https://doi.org/10.1144/gsjgs.148.6.1101

Wheeler, J. (2014). Dramatic effects of stress on metamorphic reactions. Geology, 42(8), 647-650. https://doi.org/10.1130/G35718.1

Yamato, P., \& Brun, J. P. (2017). Metamorphic record of catastrophic pressure drops in subduction zones. Nature Geoscience, 10(1), 46-50. https://doi.org/10.1038/ngeo2852

Yang, J. J., Huang, M. X., Wu, Q. Y., \& Zhang, H. R. (2014). Coesite-bearing eclogite breccia: Implication for coseismic ultrahigh-pressure metamorphism and the rate of the process. Contributions to Mineralogy and Petrology, 167(6), 1-17. https://doi.org/10.1007/ s00410-014-1013-7

Zhong, X., Vrijmoed, J., Moulas, E., \& Tajčmanová, L. (2017). A coupled model for intragranular deformation and chemical diffusion. Earth and Planetary Science Letters, 474, 387-396. https://doi.org/10.1016/j.epsl.2017.07.005 